Chapter 10

\title{
Drug Carrier Systems Using Chitosan for Non Parenteral Routes
}

\author{
Clara Luisa Domínguez-Delgado, \\ Isabel Marlen Rodríguez-Cruz, \\ Enrique Fuentes-Prado, José Juan Escobar-Chávez, \\ Gustavo Vidal-Romero, Lorena García-González and \\ Rafael Iván Puente-Lee
}

Additional information is available at the end of the chapter

http://dx.doi.org/10.5772/57235

\section{Introduction}

A safe and efficient drug carrier must offer protection to human tissues in which it is administered as well as protection to the drugs against degradation, improve therapeutic effect, prolong biological activity, control drug release rate, and decrease the frequency of administration. These characteristics could be achieved by using chitosan to prepare carriers of drugs. It is almost the only cationic polysaccharide in nature with a great innate medical potential. Chitosan, a cationic polymer of natural origin, is a remarkable example of an excipient which currently has enormous potential for using in pharmaceutical dosage forms because of its properties as polyelectrolyte with reactive functional groups, gel-forming capability, high adsorption capacity, biodegradability and biocompatible and non-toxic to living tissues as well as having antibacterial, antifungal and antitumor activity. These functional properties provide suitability and extensive pharmaceutical applications such as for the preparation of drug delivery systems (drug conjugate, micro/nanoparticles, hydrogels, emulsions, biodegradable release system, etc.) and for regenerative medicine for many components such as proteins/ peptides, growth factors, anti-inflammatory drugs, antibiotics intended to be administered in non parenteral routes (oral, topical, intranasal, vaginal, rectal and ocular). Interesting applications of chitosan has been receiving considerable attention since it has been developed systems more versatile by the incorporation of chitosan and other components in novel systems. They have provided a strategy for the functionalization by modulating physico- 
chemical properties (hydrophilicity, surface charge, etc.) improving the encapsulation, stability, and protection of drugs. The recent development of nanotechnology and the various processes of funcionalization of chitosan have increased and improved its functionality as drug carrier.

This work reviews the drug carrier systems using chitosan to improve and increase the delivery of drugs for non parenteral routes. The most important properties of chitosan, the types of systems intended to be used for non parenteral routes, the strategies for the functionalization of chitosan systems by the incorporation of other components, advantages and limitations, and the relevance of pharmaceutical, pharmacological and toxicological experimental studies are reviewed in different drug carrier systems from chitosan.

\section{General characteristics of chitosan}

Chitosan is an abundant polysaccharide, it has the peculiarity of being the unique cationic biopolymer of natural origin [1,2]. It is obtained from the chitin, the most second abundant polysaccharide in the nature $[3,4]$. The wide variety of natural sources of chitosan include: structural components of the cell walls of certain fungi, algae and bacteria species, and in the egg shells of nematodes. Nevertheless, the principal source is the shells of mollusks and the exoskeleton of the phylum Arthropoda such as Crustacea, Insecta, and Myriapoda subphylums $[3,5-7]$. The principal industrial source of chitosan is the chitin of the crustacean shell wastes such as crab (10\% of chitin), shrimp ( $22 \%$ of chitin), lobster (17\% of chitin) and crawfish ( $36 \%$ of chitin) $[8,9]$. Although it is much less common than the natural occurrence of chitin, it is possible to obtain chitosan directly from a natural source, e. $g$, the structure of certain fungi [10]. However, chitosan is generally produced by chemical processes that involve the alkaline deacetylation of chitin aided by thermochemical conditions or by enzymatic hydrolysis in presence of a chitin deacetylase $[2,6,11]$.

\subsection{Chemical properties}

The chemical structure of chitosan is ideally formed only by 2-amino-2-deoxy- $\beta$-D-glucopyranose, the deacetylated form of D-glucosamine, and chitin is ideally formed only by 2acetamido-2-deoxy- $\beta$-D-glucopyranose, which is the acetylated form of D-glucosamine. However, the real found structure of chitosan, as well as the one of chitin, is a copolymer of 2amino-2-deoxy- $\beta$-D-glucopyranose and 2 -acetamido-2-deoxy- $\beta$-D-glucopyranose, in which both the deacetylated and the acetylated forms of D-glucosamine are randomly distributed along the whole copolymer chain. This is the reason why chitosan comprises a wide group of fully and partially deacetylated chitins. The two kind of D-glucosamine residues are linked by $\beta(1 \rightarrow 4)$-glycosidic bonds. It is accepted chitosan is composed predominantly of the deacetylated form of D-glucosamine [1, 2, 4, 6, 7, 11-13]. The Figure 1 represents the chemical structure of chitin and chitosan.

Commercial chitosans have a deacetylation degree of $85 \%$, and its elemental composition is $44.11 \%$ of carbon, $7.97 \%$ of nitrogen, and $6.84 \%$ hydrogen [6]. When chitosan is obtained 
using an alkaline process, the degree of deacetylation can be controlled if the time, temperature and the concentration of alkali and chitin are also controlled. In addition to these processing factors, the degree of acetylation, the distribution of acetyl groups along the biopolymer chain, and the molecular size distribution of chitosans change depending of the source of chitosan. All these factors determine chitosan physicochemical and biological properties [13, 14].

Chitosan is distinguished by its solubility in dilute aqueous acid solutions derived from its polycationic character [9] and its insolubility in most solvents. In function of deacetylation degree, a chitosan polymer becomes soluble in dilute acidic medium; the minimum deacetylation level for solubilizing is $40-60 \%$. The solubility of the polymer, the inter-chain interactions due to hydrogen bonds and the hydrophobic character of the acetyl group are affected by the distribution of $\mathrm{N}$-acetyl groups along the biopolymer chain [13]. The solubility of chitosan is also affected by the formation of crystalline structures as a result of intra- and inter-macromolecular hydrogen bonds in the solid state; crystalline domains appear to be the main factor limiting for chitosan aqueous solubility [15]. Between acidic and neutral pH conditions, chitosan develops positive net charges because of its polycationic nature [9, 13]. Chitosan is positively charged due to primary amino groups, the magnitude of the charge density is dependent on the degree of deacetylation, $\mathrm{pH}$, and ionic strength [9]. In weakly acidic aqueous solutions of inorganic acids (phosphoric and sulfuric acids) and organic acids (formic, acetic, tartaric, and citric acids), amino groups are partially protonated, while a total protonation is reached at $\mathrm{pH} 4.0$ [15]. Another chemical characteristic of chitosan is its metal binding capacity attributed to its chelating ability of the amine groups [5]. Table 1 shows some intrinsic (structural characteristics of chitosan) and extrinsic parameters that affect some functionality parameters [16-18].
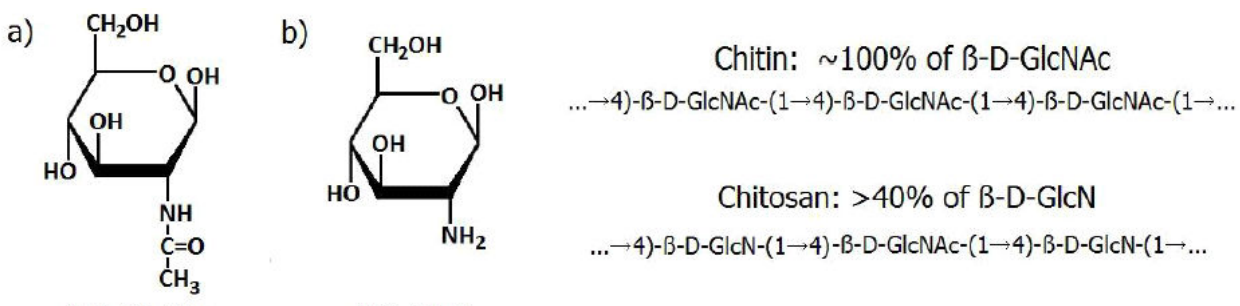

B-D-GICNAC

\section{B-D-GlCN}

Figure 1. Chemical structures of chitin and chitosan and their monomers: a) 2-acetamido-2-deoxy- $\beta$-D-glucopyranose or $\beta$-D-GlcNAc and b) 2-amino-2-deoxy- $\beta$-D-glucopyranose or $\beta$-D-GlcN.

\subsection{Physical properties}

Physical properties of chitosan depend of factors as the molecular weight distribution, the acetylation degree and the source of chitosan. In Table 2 are listed some physical properties of reported in scientific literature and commercial chitosans from different sources [19-22]. The solution conformation of chitosan can occur as rod-like, spherical or random coil conformations in function of the molecular weight distribution and degree of acetylation; the molecular 
mass affects the intrinsic viscosity and radius of gyration [23] while the degree of acetylation determines in turn the electric charge which is directly related to the solution conformation of chitosan [20]. When the charge on the chitosan chain increases, its conformation in solution expands and the viscosity increases substantially [24].

\begin{tabular}{|c|c|c|}
\hline $\begin{array}{l}\text { Functionality } \\
\text { parameter }\end{array}$ & $\begin{array}{l}\text { Intrinsic and extrinsic chitosan } \\
\text { factors that affect its } \\
\text { functionality }\end{array}$ & $\begin{array}{l}\text { Correlation between chitosan functionality parameters } \\
\text { and structural characteristics }\end{array}$ \\
\hline Viscosity & $\begin{array}{l}\text { - Molecular weight } \\
\text {-Deacetylation degree } \\
\text {-Presence of contraions } \\
\text {-pH } \\
\text { - Solvent }\end{array}$ & $\begin{array}{l}\text {-Viscosity of the chitosan solutions is affected by the } \\
\text { presence of the amino groups with a pKa value of } 6.3 \text { (as a } \\
\text { strong base its polielectrolyte nature affects the } \\
\text { hydrodynamic ratio in solution) [16]. }\end{array}$ \\
\hline $\begin{array}{l}\text { Hydrogels } \\
\text { formation }\end{array}$ & $\begin{array}{l}\text {-Molecular weight } \\
\text { - Deacetylation degree } \\
\text { - Chitosan concentration } \\
\text {-Presence of contraions } \\
\text {-pH } \\
\text { - Temperature }\end{array}$ & $\begin{array}{l}\text {-At pH above } 7 \text { and at low temperatures }\left(\approx 25^{\circ} \mathrm{C}\right) \text { the } \\
\text { hydrogels are greatly swollen [17]. } \\
\text { - Hydrogels are more compact and irregular when the } \\
\text { deacetylation degree (D.D.) of chitosan is increased [18]. }\end{array}$ \\
\hline Biodegradation & $\begin{array}{l}\text {-Molecular weight } \\
\text {-Deacetylation degree }\end{array}$ & $\begin{array}{l}\text { - Lower molecular weights leads to a faster biodegradation } \\
\text { rates than higher molecular weights. } \\
\text {-Deacetylation degree is determinant, increasing the } \\
\text { presence of charged moieties leads to faster degradation } \\
\text { rates. }\end{array}$ \\
\hline Solubility & $\begin{array}{l}\bullet \text { Acid concentration } \\
\text { - Ionic strength } \\
\text { - Deacetylation degree }\end{array}$ & $\begin{array}{l}\text {-Chitosan is soluble at a higher concentration of hydrogen } \\
\text { ions (below at a pH of 6) [16]. }\end{array}$ \\
\hline
\end{tabular}

Table 1. Correlation of intrinsic properties and extrinsic factors that affect its functionality and structural conformation

\begin{tabular}{lcccc}
\hline Source & Housefly larvae & SeaCure+210 & Crawfish & Shrimp shells \\
\hline Color & White & & White & White to beige \\
\hline Appearance & Powder & & Powder & Powder/chips \\
\hline Granularity (mm) & 0.245 & & & \\
\hline Ph & 6.96 & 89 & 73 & $>75$ \\
\hline D. D. (\%) & 83.1 & $540 \mathrm{ml} / \mathrm{g}[\mathrm{\eta}]$ & $563.7 \mathrm{cP}$ & \\
\hline Viscosity & $347 \mathrm{mPa} . \mathrm{s}$ & 1.72 & 0.23 (tapped) & $0.15-0.3$ \\
\hline Density (g/ml) & {$[19]$} & {$[15]$} & {$[21]$} & {$[22]$} \\
\hline Reference & & & & \\
\hline
\end{tabular}

Table 2. Some physical properties of reported in scientific literature and commercial chitosans 
Rheological properties of chitosan solutions are independent of the ionic strength and the $\mathrm{pH}$, this behavior can be related to the fact that the ionic strength within certain range does not affect the conformation in solution [23, 25]. In organic acid solutions as acetic acid ones, the viscosity curves for chitosan solutions consist of two distinct viscosimetric behaviors, the first one is a Newtonian zero-shear viscosity region and second one is a shear rate dependent apparent viscosity region. An increase in chitosan concentration produces a pseudoplastic behavior, i. e., a higher shear rate dependence of viscosity [9] while at a lower concentration exhibits a shear thinning behavior [25]. The pseudoplastic behavior is explained because as the polymer concentration increased, the freedom of movement of the individual chains becomes more restricted due to the correspondingly increased number of entanglements between chitosan chains [9]. Table 3 shows viscosities of various chitosan samples [21, 26-29]. Because chitosan undergoes acid-catalyzed hydrolysis, chitosan presents an irreversible decrease in viscosity in dilute acid medium [28], the degree of hydrolysis depends on the molecular weight and degree of acetylation: the higher the values of both parameters, the quicker decrease in the viscosity and, consequently, in the viscosity-average molecular weight [29].

Due to its degradation in acidic media, chitosan dissolved quickly after swollen in gastric juice and could not achieve sustained release in the gastrointestinal tract [30]. In order to obtain chitosan derivatives with new functionality and to extend its uses in a greater number of pharmaceutical applications, chitosan has been subjected to various chemical modifications. The chitosan structure has been modified through trimethylation, N-succinylation, thiolation, azidation, sugar-modified chitosan, chitosan-dendrimer hybrids, cyclodextrin-linked chitosans, crown-ether-bound chitosan, chemical grafting of chitosan, enzymatic modification of chitosan. These reactions yield chitosan-based derivatives that retain the biodegradability and non-toxicity characteristic of chitosan [1].

Chitosan is able to form physical gels, these gels retain the main properties of this polysaccharide, in particular, biocompatibility. The process of gel formation depends on the initial concentration of the polymer and charge density, which is determined by the degree of deacetylation [31]. The degree of hydration of chitosan hydrogels are affected by the molecular weight of chitosan [32]. Chitosan hydrogels have been investigated as potential vehicles for targeted drug delivery [15] specially seems to be suitable for sustained-release drug [32, 33].

Polycationic character of chitosan opens the possibility for interactions with negatively charged molecules (anions and polyanions) [34] and allows the forming of polyanion-chitosan complexes with polyanions such as heparin, carboxymethylcellulose, carrageenan, alginate, Pluronic, dextran sulfate, and xanthan have been produced [35-51]. The complexes formed by chitosan with other polymers can be divided into hydrogen bonding complexes, polyelectrolytes complexes, coordination complexes and self-assembly complexes based on dominant intermolecular interactions [52]. Some chitosan-based non-stoichiometric polyelectrolyte complexes are soluble at physiological $\mathrm{pH}$ and ionic strength [53], because polyelectrolyte complexes are formed in aqueous solutions, it should be taken into account molecular information as the molecular weight of chitosan, its mass distribution, the degree of deacety- 
lation, the location of free and acetylated amino groups in the polymer chain, chain length, and conformation of molecules in solution [34]. The synthesis mechanism of chitosanpolyanions complexes can be the result of changing the chemical structure of component polymers, such as molecular weight, flexibility, functional group structure, charge density, stereoregularity, and compatibility, as well as synthesis conditions: $\mathrm{pH}$, ionic strength, concentration, mixing ratio, and temperature [30].

\begin{tabular}{|c|c|c|c|c|}
\hline Preparation method & $\begin{array}{l}\text { D. D } \\
(\%)\end{array}$ & M. W. (kDa) & Viscosity & Reference \\
\hline $\begin{array}{l}\text { Oxidative fragmentation }\left(1 \% \mathrm{NaNO}_{2}\right) \text { of } \\
\text { chitosan }\end{array}$ & 91.3 & 659.4 & $\begin{array}{l}1.05 \mathrm{dL} / \mathrm{g} \text { (intrinsic, in } 0.25 \mathrm{mM} \\
\text { acetate buffer, } 0.05-0.3 \mathrm{~g} / \mathrm{dl} \text { of } \\
\text { chitosan, } 25^{\circ} \mathrm{C} \text { ) }\end{array}$ & {$[26]$} \\
\hline $\begin{array}{l}\text { Oxidative fragmentation }\left(4 \% \mathrm{NaNO}_{2}\right) \text { of } \\
\text { chitosan }\end{array}$ & 90.19 & 864.2 & $\begin{array}{l}0.21 \mathrm{dL} / \mathrm{g} \text { (intrinsic, in } 0.25 \mathrm{mM} \\
\text { acetate buffer, } 0.05-0.3 \mathrm{~g} / \mathrm{dl} \text { of } \\
\text { chitosan, } 25^{\circ} \mathrm{C} \text { ) }\end{array}$ & {$[26]$} \\
\hline $1 \% \mathrm{NaOH}, 21 \mathrm{hr}, 4 \% \mathrm{HCl}, 2 \mathrm{hr}$ & 75.9 & $\begin{array}{c}\text { Not } \\
\text { determined }\end{array}$ & $\begin{array}{l}830 \text { cP ( } 1 \% \text { acetic acid, } 1 \% \\
\text { chitosan) }\end{array}$ & {$[27]$} \\
\hline $4 \% \mathrm{HCl}, 2 \mathrm{hr}, 1 \% \mathrm{NaOH}, 21 \mathrm{hr}$ & 76.3 & $\begin{array}{c}\text { Not } \\
\text { determined }\end{array}$ & $\begin{array}{l}2919 \text { cP (1\% acetic acid, 1\% } \\
\text { chitosan) }\end{array}$ & {$[27]$} \\
\hline $\begin{array}{l}\text { Demineralization } 1 \mathrm{~N} \mathrm{HCl}, 30 \text { min, room } \\
\text { temperature after decolorization } 0.315 \% \\
\mathrm{NaOCl}, 5 \mathrm{~min} \text {, room temperature }\end{array}$ & 73 & 10.59 & $\begin{array}{l}563.7 \mathrm{cP}(1 \% \text { acetic acid, } 1 \% \\
\left.\text { chitosan, } 25^{\circ} \mathrm{C}\right)\end{array}$ & {$[21]$} \\
\hline $\begin{array}{l}\text { Deproteinization } 3.5 \% \mathrm{NaOH}, 2 \mathrm{hr}, 65^{\circ} \mathrm{C} \\
\text { after decolorization } 0.315 \% \mathrm{NaOCl}, 5 \mathrm{~min} \text {, } \\
\text { room temperature }\end{array}$ & 70 & 9.63 & $\begin{array}{l}444.9 \mathrm{cP} 1 \%(1 \% \text { acetic acid, } 1 \% \\
\left.\text { chitosan, } 25^{\circ} \mathrm{C}\right)\end{array}$ & {$[21]$} \\
\hline
\end{tabular}

Table 3. Viscosity of chitosan related to deacetylation degree (D. D. ), molecular weight (M. W. ) of chitosans produced by different methods.

In addition to the electrical charge, dipole-dipole interactions, as well as hydrogen and hydrophobic bonds are determinant for the formation of complexes with polyanions [34]. As a matrix for releasing drugs, chitosan complexes must allow the controlled release either modulating tissue drug levels or spatially-placing (or temporarily-placing) a drug in some region of the body to maintain efficacy and stability of drugs within the matrix. For drug delivery systems for gastrointestinal, respiratory, ophthalmologic, cervical, and vaginal routes, the mucins are hydrophilic saline gels that are thickened by natural anionic glycoproteins. Here, a cationic polymer as chitosan is ideal [52].

\subsection{Biological properties}

Chitosan has excellent properties such as hydrophilicity, biocompatibility, biodegradability, antibacterial and adsorption applications, and a very low toxicity [54-57]. The biocompatibility 
of chitosan is generally regarded as the ability of the newly developed material to interact with living cells, tissues, or organs by not being toxic or injurious and not triggering immunological reactions or rejections while functioning appropriately in vitro and in vivo [57]. Accordingly the features mentioned above, besides the chitosan being used for drug delivery, is used in tissue engineering, gene delivery, nasal drug and vaccine delivery [58]. The formulation of chitosan with a drug may alter the pharmacokinetic and biodistribution profiles, and for pharmaceutical applications it is necessary to take in account the route of administration, its concentration, contact time and cell types that enter in contact with chitosan or chitosan complexes [58-63]. In Table 4 are listed some biological and toxicological properties of chitosan in several biological systems [64-75].

Due to its good biocompatibility and biodegradability properties, chitosan provides a useful excipient for mucoadhesive drug delivery systems in order to prolong the mucosal residence time. An inconvenient issue about chitosan, it is that glucosamine from shellfish may not be suitable for allergic people to shellfishes [10]. Although chitosan has not yet been related directly to cases of allergic reactions, some cosmetics or nutraceuticals products prepared with chitosan are related to skin irritation or even anaphylaxis [21, 76, 77]. It is possible that proteins from shellfish such as tropomyosin and arginine kinase remain as residues on the chitosan and chitin, being these substances responsible for such allergic reactions [78]. As a result of this review, no allergenic reactions produced to nasal membranes have been found reported. Arai et al. found that chitosan has an LD50 comparable to sucrose of $>16 \mathrm{~g} / \mathrm{kg}$ in oral administration to mice [79]. No oral toxicity was found in mice treated with $100 \mathrm{mg} / \mathrm{kg}$ chitosan nanoparticles (80 kDa, 80\% DD) [80]. Exposure of rat nasal mucosa to chitosan solutions at $0.5 \%$ (w/v) over $1 \mathrm{~h}$ caused no significant changes in mucosal cell morphology compared to control [81]. From most studies reported it appears that chitosan shows minimal toxic effects and this approves its adoption as a safe material in drug delivery. Others authors studied the safety of a chitosan bandage in shellfish allergic patients (shellfish allergy prevalence of $2.8 \%$ in adults) showing that all subjects tolerated the bandage without reaction. Although larger cohort studies should be considered, the results from this study are encouraging and consistent with two previous studies demonstrating the safety of other chitin-derived products in patients allergic to shellfish [82].

An important aspect in the use of polymers as drug delivery systems is their metabolic fate in the body or biodegradation [54]. Degradation of chitosan by thermal, acidic, enzymatic, and irradiation process have been reported [28, 29, 60-63, 83- 85]. In general, both rate and extent of chitosan biodegradability in living organisms are dependent on the degree of deacetylation [54]. Enzymatic degradation of chitosan is sensitive to the supermolecular structure of the polymer [83], in human body lisozyme produces the hydrolysis of chitosan [86]. Aminosugars released as a result of its biodegradation can be used in the metabolic pathways of glycosaminoglycans and glycoproteins in the body $[87,88]$. In the stomach, some chemical degradation is wide catalysed by gastric acid [54], but it is not hydrolyzed by human digestive enzymes [69], its lack of absorption in the human body provides chitosan a function as dietary fiber [56]. In the case of the systemic absorption of hydrophilic polymers such as chitosan, they should have a suitable Mw for renal clearance [54]. 


\begin{tabular}{|c|c|c|c|c|}
\hline & D. D (\%) & M. W. & $\begin{array}{l}\text { Concentration of } \\
\text { chitosan }\end{array}$ & Reference \\
\hline \multicolumn{5}{|c|}{ Biological activity } \\
\hline $\begin{array}{l}\text { Antitumor activity against } \\
\text { HepG2, A549, and PC3 model } \\
\text { tumor cell }\end{array}$ & $\begin{array}{r}100 \\
87.5\end{array}$ & $\begin{array}{l}\text { Pentamers } \\
\text { Octamers }\end{array}$ & $\mathrm{IC} 50<50 \mu \mathrm{g} \cdot \mathrm{mL}-1$ & [64] \\
\hline $\begin{array}{l}\text { Prevent leakage and bleeding } \\
\text { from lung punctures }\end{array}$ & $\begin{array}{l}99 \\
98\end{array}$ & $\begin{array}{l}230 \mathrm{kDa} \\
300 \mathrm{kDa}\end{array}$ & $\begin{array}{l}2.3 \%(w / v) \\
2.3 \%(w / v)\end{array}$ & {$[65]$} \\
\hline $\begin{array}{l}\text { Reduction of } 25-30 \% \text { in } \\
\text { plasmatic cholesterol in rats }\end{array}$ & & & $5 \%$ of the diet & [66] \\
\hline $\begin{array}{l}\text { Decreasing of fat digestibility, } \\
\text { mineral absorption and vitamin } \\
\text { E level in rats fed with high-fat } \\
\text { diets }\end{array}$ & 90 & Not specified & $50 \mathrm{~g} / 100 \mathrm{~g}$ of solids & [67] \\
\hline $\begin{array}{l}\text { Prevention the symptoms of } \\
\text { isoprenaline-induced } \\
\text { myocardial infarction in rats }\end{array}$ & $85-87$ & $750 \mathrm{kDa}$ & $\begin{array}{c}2 \% \text { of the diet for } 60 \\
\text { days }\end{array}$ & [68] \\
\hline $\begin{array}{l}\text { Reduction of body weight and } \\
\text { plasma triacylglycerol } \\
\text { concentration in mice }\end{array}$ & Not specified & $46 \mathrm{kDa}$ & $\begin{array}{l}300 \text { mg/Kg daily } \\
\text { administrated }\end{array}$ & [69] \\
\hline \multicolumn{5}{|c|}{ Antibacterial activity } \\
\hline Against E. coli & $\begin{array}{l}20 \% \\
11 \%\end{array}$ & $\begin{array}{l}55,155 \\
5,300\end{array}$ & $\begin{array}{c}\text { 50-100 ppm } \\
\text { 2500-10000 ppm }\end{array}$ & {$[70,71]$} \\
\hline Against L. monocytogenes & 10 (56 kDa) & 5,150 & 1000 ppm & {$[72]$} \\
\hline Against S. typhimurium & $15-25 \%(150 \mathrm{kDa})$ & 5,150 & 1000 ppm & {$[72]$} \\
\hline $\begin{array}{l}\text { Maximum inhibition of } \\
\text { absorption of Streptococcus } \\
\text { sobrinus by hydroxyapatite } \\
\text { (anti-plaque activity) }\end{array}$ & $50-60 \%$ & $5-6$ & 250 ppm & [73] \\
\hline \multicolumn{5}{|c|}{ Toxicity } \\
\hline $\begin{array}{l}\text { Aspartic acid salt of chitosan in } \\
\text { B16F10 cells }\end{array}$ & $78 \%$ & $<50$ & (IC50) $2.50 \mathrm{mg} / \mathrm{mL}$ & [74] \\
\hline $\begin{array}{l}\text { Aspartic acid salt of chitosan in } \\
\text { Caco- } 2 \text { cells }\end{array}$ & $87 \%$ & $20,45,200,460$ & $\begin{array}{c}(\text { IC50)670, 650, } 720 \\
\mathrm{mg} / \mathrm{mL}\end{array}$ & {$[75]$} \\
\hline
\end{tabular}

Table 4. Some biological and toxicological properties of chitosan related to deacetylation degree (D. D. ), molecular weight (M. W. ) and its concentration in several biological systems. 
The administration of chitosan in humans has been extensively studied (Table 5) [89-94]. The chitosan exhibits a hypocholesterolemic effect, the administration of chitosan, regardless of their molecular weight, coupled with ascorbic acid, produce a decreased fat absorption. When chitosan enters in contact with gastric fluids, forms a gel that traps lipids preventing their absorption in the intestine. Sodium ascorbate enhances the gelling and flexibility of chitosan, increasing the amount of fat that is stuck [95]. By blocking the absorption of fat is inhibited the atherosclerotic plaque formation, reducing the risk of atherosclerosis in hypercholesterolemic persons [88], besides that no deterioration occurs in the intestinal mucosa causing antihypercholesterolemiants as cholestyramine [96].

Fat absorption depends on the degree of deacetylation and the viscosity of chitosan. The greater degree of deacetylation and a high viscosity of the chitosan cause a higher absorption of dietary fat [66]. Chitosan also reduces cholesterol, urea and creatinine, and increases of hemoglobin levels, which may be used as coadyuvate in the treatment of patients with kidney failure [89]. Chitosan can cause wound healing and fibrosis decreasing mortality genitourinary surgery, and produce a hemostatic effect, which is attributed to the interaction between the cell membrane of the erythrocytes and chitosan, being this interaction independent of the classical cascade of coagulation [97].

\begin{tabular}{llll}
\hline Health problem & Treatment & Effect & Reference \\
\hline Renal failure & $45 \mathrm{mg} /$ tablet per 12 weeks & $\begin{array}{l}\text { Reduction of urea, cholesterol, } \\
\text { creatinine levels in serum. }\end{array}$ & [89] \\
\hline Obesity & $\begin{array}{l}\text { Four tablets, } 400 \mathrm{mg} / \text { tablet, per } \\
\text { day with low calorie diet for } 4 \\
\text { weeks }\end{array}$ & $\begin{array}{l}\text { Variable adverse effects in 5\% of } \\
\text { treated subjects }\end{array}$ & [90] \\
\hline Overweight & $\begin{array}{l}\text { 0, } 4.5,6.75 \mathrm{~g} \text { of chitosan per day } \\
\text { for eight weeks, no dietary } \\
\text { restrictions }\end{array}$ & $\begin{array}{l}\text { No effect on serum content of } \\
\text { vitamins A, E, D, alpha carotene, beta } \\
\text { carotene. Modest reduction in } \\
\text { plasma cholesterol concentrations }\end{array}$ \\
\hline [91]
\end{tabular}

Table 5. Effects of chitosan and complexes containing chitosan administrated on humans with different health problems. 


\subsection{Chitosan and chitin biodegradability}

Biodegradation of chitosan and chitin implies the cleaving of the $\beta(1 \rightarrow 4)$-glycosidic bond between the two kind of D-glucosamine residues that form its chemical structure. Biodegradation of chitosan has been assessed by enzymatic methods using enzymes from different sources. The lysozyme (EC 3. 2. 1. 17) is an enzyme which degrades chitosan and chitosanconjugates by cleaving the $\beta(1 \rightarrow 4)$ bonds between $\mathrm{N}$-acetyl-D-glucosamine residues; lysozyme also degrades $\beta(1 \rightarrow 4)$-glycosidic bonds between the N-acetylmuramic acid and N-acetyl-Dglucosamine residues in peptidoglucan [98]. Lysozyme exists in various human body fluids and tissues with concentrations from 4 to $13 \mathrm{mg} / \mathrm{L}$ in serum and from 450 to $1230 \mathrm{mg} / \mathrm{L}$ in human tears [99]. The rate of biodegradation of chitosan by the lysozyme is affected by the degree of deacetylation; initial degradation rates increase with a decreasing degree of deacetylation.

Some chitosan derivatives exhibit a faster degradation rate than chitosan, for example with the increasing of the molar ratio of glycolic acid to chitosan of poly(glycolic acid) grafted chitosan the rate of degradation gradually increased [100].

Chitin polyphorms exhibit different rates of degradation. Lysozyme degrades $\beta$-chitin more readily than $\alpha$-chitin due to the weak intermolecular forces of the latter. In $\beta$-chitin the degree of deacetylation is decisive for the degradation behavior of chitin [101].

Chitinases are enzymes present in fungi, insects, and bacteria, these enymes degrades chitin to olygosaccharides. In general, microbial endo-chitinases hydrolyze $\beta(1 \rightarrow 4)$-glycosidic bonds randomly. Chitinases isolated from different organisms have widely different characteristics. In human the presence of chitinases is associated to allergic reactions. Human chitinases with enzymatic activity have been identified, but they have not been investigated with regards to the degradation of chitosan and/or its derivatives [52].

\subsection{Toxicological properties}

Biodistribution, in vivo and in vitro toxicity using various chitosans of different molecular weights and degrees of deacetylation and derivatives would provide data that could help correlate chitosan's structure and safety profile [48]. Some derivatives increase in toxicity and any residual reactants must be carefully removed [49]. In laboratory mice, the $\mathrm{LD}_{50}$ of chitosan is similar to that of salt or sugar (16 g/kg of body weight) [50].

\section{Drug carrier systems using chitosan intended to be used for non parenteral routes}

A considerable amount of work has been published on chitosan and its potential use in drug delivery systems. In recent years considerable research has been focused on noninvasive routes, such as mucosal (oral, buccal, nasal, pulmonary and vaginal) and (trans)dermal. Chitosan has a cationic character because of its primary amino groups. These primary amino 
groups are responsible for properties such as controlled drug release, mucoadhesion, in situ gellation, transfection, permeation enhancement, and efflux pump inhibitory properties.

The mucoadhesive properties are also based on its cationic character. The mucus gel layer exhibits anionic substructures in the form of sialic acid and sulfonic acid substructures. Based on ionic interactions between the cationic primary amino groups of chitosan and these anionic substructures of the mucus, mucoadhesion can be achieved. In addition, hydrophobic interactions might contribute to its mucoadhesive properties. Moreover, several studies have shown the effects of chitosan systems for the drug delivery. The molecule has been widely used in a variety of pharmaceutical multipurpose excipients capable of increasing aqueous solubility and drug stability [102].

\subsection{Nasal delivery systems}

Owing to nasal obstacles such as low membrane permeability, a short local residence time, and high turnover rate of a secretion in nasal cavities, the bioavailability of nasally administered drugs is often comparatively poor [103]. In order to overcome those problems, chitosan particles or polyelectrolyte complexes have been studied for nasal delivery of therapeutic proteins [104-106]. It was found that insulin loaded chitosan nanoparticles enhance nasal drug absorption to a greater extent than relevant chitosan solutions.

Chitosan has been also used recently via intranasal in many studies particulary in vaccines as a potent mucosal adjuvant. In a study, the matrix protein 1 , which is highly conserved in all influenza A strains, was purified and used for immunization (twice at an interval of 3 weeks) of BALB/c mice by intranasal drip using chitosan as adjuvant to test the efficacy as vaccine. The results showed that nasal administration of $100 \mu \mathrm{g}$ of the matrix protein 1 in combination with chitosan could not only completely protect the mice effectively against the homologous virus (H9N2) but also protect $70 \%$ and $30 \%$ of the mice against the heterologous H1N1 and $\mathrm{H} 5 \mathrm{~N} 1$ viruses, respectively, indicating that the matrix protein 1 is a candidate antigen for a broad-spectrum influenza virus vaccine and the adjuvant chitosan significantly improved the efficacy of the vaccine. This vaccine could provide effective protection against unknown influenza virus infection in future [107].

Microparticles (with suitable range for vaccine delivery) and gels using chitosans with different molecular weight and solubility as adjuvant/delivery system for mucosal (nasal) immunization against bovine herpes virus $1(\mathrm{BHV}-1)$ showed that when the virus was incorporated into microparticles, the particle size was increased $(p<0.05)$. Narrower particle size distribution was obtained with water soluble chitosan compared to that of base chitosan particles at different molecular weights $(p<0.05)$. This difference can be attributed to difference in solubility of chitosans [108]. Similar results were reported in other studies [109-112]. With blank microparticles prepared with base chitosan at different molecular weights, the surface appearance and morphology were observed to be similar (with a smooth surface and spheroids). When the particles were loaded with the antigen; the surface appearance of the microparticles was changed with the increasing molecular weight of chitosan (Figure 2). These results suggest that antigen is entrapped within the microparticles, as well as associated with the surface of the microparticles [108]. Similarly, increased particle size and surface roughness 
with antigen loading has been reported by other groups $[113,114]$. These systems are promising adjuvant/delivery systems for non-invasive delivery of antigen tested as well as for other antigens.

Moreover, the nasal administration of vaccines can induce specific IgA antibody responses at distant mucosal sites, including the upper and lower airway mucosa and the small and large intestines, as well as the nasopharynx, salivary glands, genital tract, and tonsils, because of the dissemination of antigen-specific lymphocytes in the common mucosal immune system (immunocompetent cells in the body, such as M-cells, T-cell, B-cell, dendritic cells, and macrophages) [114-116].

\subsection{Oral delivery systems}

Chitosan-based formulations have been used for the delivery of drugs to specific sites of the body such as oral cavity, stomach, small intestine and colon. The site-specific delivery of the drug to the oral cavity can be used to treat a number of diseases of the mouth, such as stomatitis, periodontal disease, fungal and viral infections, and oral cavity cancers, thereby avoiding the first pass metabolism effect. In this sense, some points should be considerate for buccal administration of drugs, such as maintain the device in its position for many hours against buccal motion and salivary flow, which could reduce the mucosal absorption. Consequently, the dosage form must have good adhesive properties and show an efficient control of drug delivery. Investigations have shown in several studies that drug release is influenced by swelling and erosion of the matrix, whereas matrix adhesiveness can be modulated using different mixtures of polymers, both adhesive and not. Here, investigations have reported that the chitosan has good mucoadhesiveness and a significant enhancing effect on the permeation of drugs across the buccal mucosa $[117,118]$. The applications using chitosan include chlorhexidine loaded chitosan microparticles, which showed a determination effective of antibacterial activity of chitosan from thermosensitive hydrogel (with or without drugs) or as activator for the antibacterial process [119]. Chitosan microspheres based drug delivery is applicable for systemic as well as for local therapy. In case of oral drug delivery, the use of microspheres loaded with antibiotics would be beneficial for gastric diseases such as peptic ulcer [21], Helicobacter pylori, and intestinal infections, ulcerative colitis and carcinomas [20]. On the other hand, in many studies it has been demonstrated that chitosan-based formulations were superior in enhancing absorption of therapeutic proteins as well as induction of antibodies after mucosal vaccination [34-36].

With respect to the colon drug delivery, some microcrystalline cellulose core beads containing 5-aminosalicylic acid produced by extrusion-spheronization were coated with chitosan and Aquacoat ${ }^{\circledR}$ ECD mixtures. An adequated selection of the coating thickness and the chitosan level in the coat could minimize drug release in simulated intestinal fluid and provide zero order release. These products could also be used to achieve controlled release of drugs in the small intestine. Beads coated with chitosan/ Aquacoat ${ }^{\circledR}$ showed to be susceptible to the action of rat cecal and colonic enzymes and demonstrated their potential for colon specific drug delivery [120]. 


\subsection{Ocular delivery systems}

Various ophthalmic vehicles, such as inserts, ointment, suspensions, and aqueous gels, have been developed in order to lengthen the resident time of instilled dose and enhance the ophthalmic bioavailability. Chitosan based systems have the potential for improving the retention and biodistribution of drugs applied topically onto the eye. One of the pharmaceutical forms most investigated are the in situ gels, which have been developed to prolong the precorneal resident time of the drug and to improve ocular bioavailability [121-126]. The interaction and prolonged residence time of fluorescence-labelled nanoparticles prepared with chitosan was reported showing, these colloidal drug carriers remained attached to the cornea and the conjunctiva for at least $24 \mathrm{~h}$ [127]. Therefore, mucoadhesive chitosan nanoparticles may have potential as colloidal drug delivery systems for the ocular mucosa. It was demonstrated the potential of chitosan nanoparticles with cyclosporine A to improve the delivery of drugs to the ocular mucosa. Furthermore, chitosan-based colloidal systems were found to work as transmucosal drug carriers, either facilitating the transport of drugs to the inner eye or their accumulation into the corneal epithelia. The use of chitosan-based colloidal suspensions in vivo showed a significant increase in ocular drug bioavailability [128]. Additionally, bioadhesive chitosan microspheres have been also studied for ophthalmic administration, in which a high concentration of acyclovir for an extended period of time was obtained from in vivo ocular studies on rabbits. According to the authors, in addition to its mucoadhesive properties, chitosan is effective in retarding the rate of drug release [128].

Another interesting study reported chitosan microparticles to be administered via ophthalmic. The in vitro release kinetics of chitosan microparticles and their in vitro and in vivo biocompatibility and cytotoxicity on retinal cells were examinated. The results showed that chitosan microparticules were effective to obtain long-term protein or drug delivery agents to the outer segment of the retina. Chitosan microparticles exhibited enhanced encapsulation capacity and a better release profile than the Polyethylene glycol-Polylactic acid (PEG-PLA) microparticles investigated previously. However, the concentration of chitosan microparticles may be critical to determine the extent of toxicity, and the concentration required will depend on the encapsulation efficiency and on the amount of protein (or drug) required to obtain a therapeutic dose [129].

\subsection{Topical/transdermal delivery systems}

Transdermal drug delivery systems can deliver drugs for systemic effects through skin at controlled rate (can be interrupted if it necessary), with the advantage of avoiding the first pass metabolism effect [130-134]. An example of this could be obtained with the lidocaine hydrochloride-loaded transdermal chitosan patches as a drug reservoir, which released the drug in a manner prolonged at 95\% chitosan degree of deacetylation [135].

In a recent study, warfarin- $\beta$-cyclodextrin loaded chitosan nanoparticles for transdermal delivery were successfully prepared by ionic gelation method. Chitosan nanoparticles were found to be spherical, smooth and with narrow size distribution. They showed high drug entrapment efficiency and well accepted yield. The release profile from nanoparticles showed an initial burst effect followed by a slow and continuous release phase. The nanoparticle 

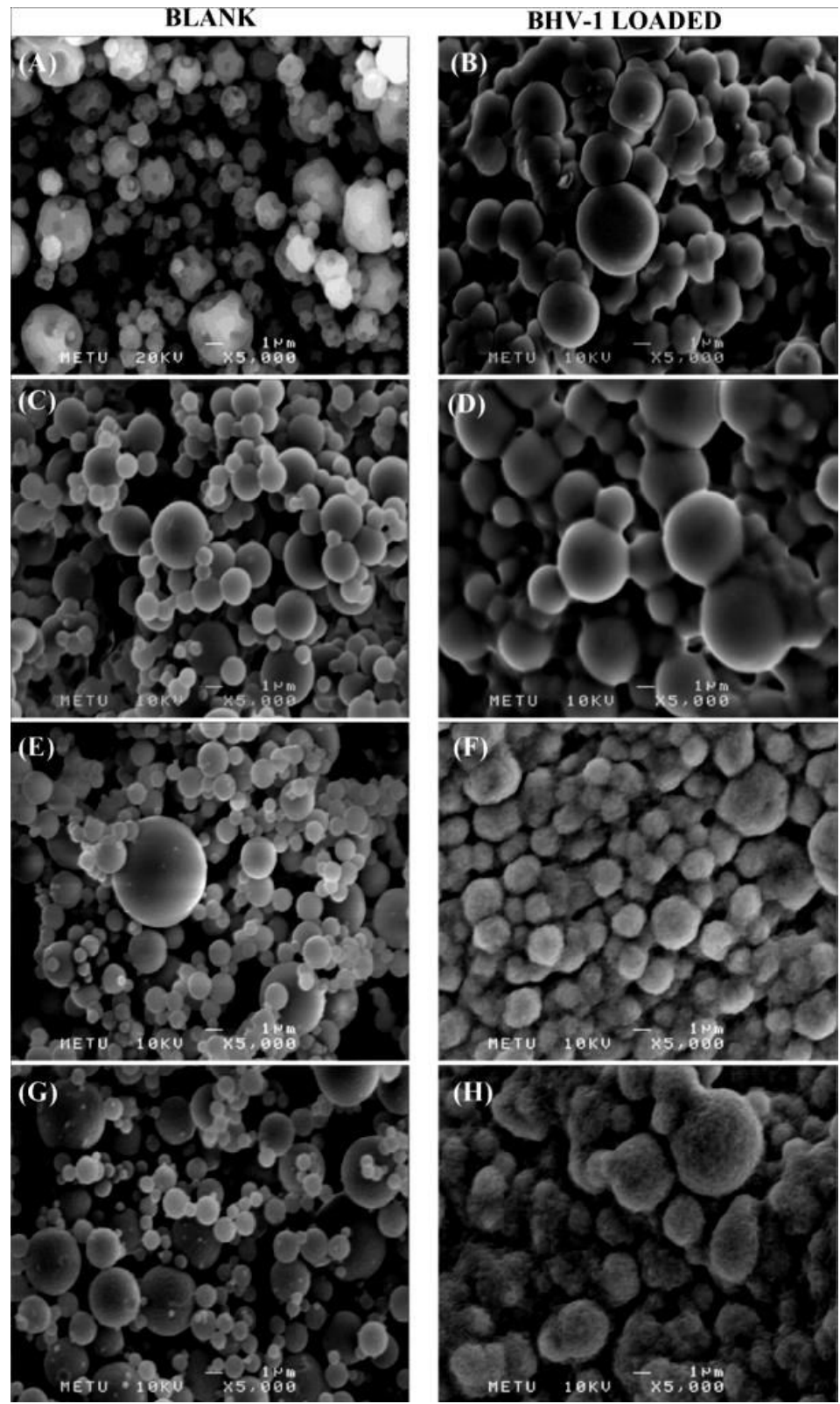

Figure 2. SEM micrographs of blank (A) and BHV-1 loaded microparticles (B) prepared with water soluble chitosan; chitosan base-low molecular weight (50-1000 kDa): blank (C), BHV-1 loaded microparticles (D); chitosan base-medium molecular weight (300-2000 kDa): blank (E), BHV-1 loaded microparticles (F); chitosan base-high molecular weight (500-5000): blank (G), and BHV-1 loaded microparticles (H). This figure is reproduced with the permission [108]. 
formulation enhanced the permeation of warfarin through excised rat skin in a constant and continuous profile. Therefore, it could be concluded that this formulation enhanced the controlled release and the permeation of warfarin, offering a promising system for the transdermal delivery [136].

\subsection{Regenerative systems}

In order to regenerate some loss or damaged tissue and organ, in vitro seeding and attachment of human cells onto a scaffold, followed by the culturing of the cells to form the new organ or tissue must to be performance to avoid some transplantation of them. Chitosan is one of the most exploited polymers for this application due to its known biocompatibility, biodegradability, antibacterial and wound-healing activities. Its use in tissue engineering stems from the capacity of chitosan (unmodified or as a derivative) to produce efficient scaffolds having desirable characteristics such as porosity, gel forming ability and high affinity to in vivo macromolecules [137]. Additionally, it has a structural similarity to glucosaminoglycans which are the major component of the extracellular matrix. Recent studies, attempted to address this issue through the conjugation of cell adhesion moieties to chitosan based materials, hence aiming to produce more physiologically relevant scaffolds that mimic of the extracellular matrix functions. In addition to provision of correct environment for cell growth and support, biodegradability of the scaffold material is also important. It is preferred that the materials are absorbed or excreted from the body without the necessity of surgical removal. The in vitro investigation of the responsiveness of articular chondrocyte-like cells using a multimembrane hydrogel of chitosan showed a large amount of cartilage-type matrix proteins were produced [138]. Chitosan has been extensively used in bone tissue engineering, since it was shown to promote cell growth and mineral rich matrix deposition by osteoblasts cells in culture [139]. Studies in order treat acute and chronic liver disease are also been investigated. Hepatoma HepG2 cells were seeded onto the microfluidic-based pure chitosan microfibers for liver tissue engineering applications without the use of any chemical additives. The results showed an aggregation of these cells forming spheroids, which also had higher liver function that was confirmed by albumin secretion and urea synthesis. This method represents a potentially useful tool for liver tissue engineering applications [140].

\section{Strategies for the functionalization of chitosan systems using other components}

Chitosan is a non-toxic, biocompatible and biodegradable polymer and has attracted considerable interest in a wide range of biomedical and pharmaceutical applications including drug delivery, cosmetics, and tissue engineering. The primary hydroxyl and amine groups located on the backbone of chitosan are responsible for the reactivity of the polymer and also act as sites for chemical modification. However, chitosan has certain limitations for use in controlled drug delivery and tissue engineering. These limitations can be overcome by chemical modification. In order to achieve high mucoadhesive properties, this polymer needs to exhibit also 
high cohesive properties as the adhesive bond otherwise fails within the mucoadhesive polymer rather than between the mucus gel layer and the polymer. In case of chitosans, however, these cohesive properties are also comparatively weak. Although they can be strongly improved by the formation of complexes with multivalent anionic drugs, multivalent anionic polymeric excipients, and multivalent inorganic anions, this strategy is only to a quite limited extent effective, as the cationic substructures of chitosan being responsible for mucoadhesion via ionic interactions with the mucus are in this way blocked. The combination of chitosan with other materials appears to be a common theme in various reports. Blending with other polymers is widely investigated. Blends with synthetic and natural polymers can imbibe the wide range of physicochemical properties and processing techniques of synthetic polymers as well as the biocompatibility and biological interactions of natural polymers.

A significantly improved oral bioavailability of buserelin was demonstrated with mucoadhesive polymers such as chitosan and carbomer to rats. This effect, however, could not be observed anymore when chitosan was combined with the polyanionic carbomer in the same formulation [141]. Trimethylation of the primary amino group of chitosan provides an even more cationic character of the polymer. When trimethylated chitosan is additionally PEGylated, its mucoadhesive properties are even up to 3. 4-fold improved [142]. Due to the immobilization of thiol groups on chitosan, its mucoadhesive properties can also be strongly improved, as the thiolated polymer is capable of forming disulfide bonds with mucus glycoproteins of the mucus gel layer, placing it among the most mucoadhesive polymers known so far [143]. In addition, as inter- and intrachain disulfide bonds are also formed within chitosan itself, thiolated chitosan exhibits substantially improved cohesive properties. Recently, the mucoadhesive properties of thiolated chitosans were even significantly further improved by the preactivation of thiol groups on chitosan via the formation of disulfide bonds with mercaptonicotinamide.

\subsection{Oral drug delivery}

Chitosan, the second most abundant polysaccharide next to cellulose, has been adopted as having great potential application as a protein drug carrier for oral administration due to its outstanding properties of non-toxicity, biocompatibility, biodegradability and low cost [144, 145]. Oral administration of drugs represents the easiest and the most convenient route of drug delivery. Therefore, the enhancement of oral bioavailability of some drugs particularly those with poor aqueous solubility, is gaining increasing attention for successful development of oral treatment. Chitosan based hydrogel systems can be designed to deliver drugs locally to the stomach or the upper part of tract to improve bioavailability. It was tested by confocal laser scanning microscopy that amoxicillin loaded $\mathrm{pH}$-sensitive hydrogels composed of chitosan and poly(g-glutamic acid) could be infiltrated in the cell-cell junctions and interact with Helicobacter pylori infection sites for the treatment of peptic ulcer [146]. Hydrogels of chitosan and polyacrylic acids containing amoxicillin and clarithromycin showed similar results. Modified chitosan hydrogels loaded with metronidazole, tetracycline and theophylline could bypass the acidic environment of the stomach and release the loaded drug into the intestine [147]. 
Another investigation reported that the oral bioavailability of acyclovir could be improved 3fold and 4-fold due to the incorporation of this drug in chitosan and thiolated chitosan, respectively. Within this study, a prolonged residence time in particular of thiolated chitosan microparticles in duodenal and jejunum regions was observed. These data need to be confirmed in human volunteers. So far, an improved oral bioavailability of various model drugs could be shown in human volunteers for mucoadhesive formulations likely because of an intimate contact of the delivery system with the absorption membrane and a prolonged mucosal residence time of the delivery systems [148].

Several systems have been proposed to encapsulate insulin to improve oral insulin bioavailability, including polymeric hydrogels polymeric solid nano-particles and liposome-based carriers [149-153]. However, limitations related to the enzymatic degradation in the gastrointestinal tract and the low permeability across the intestinal epithelium are common problems in those systems [154, 155].

Contrarily, it was reported that insulin analog can be successfully encapsulated in chitosan microspheres with a high loading content. The quaternized groups on $\mathrm{N}-[(2-$ hydroxy-3trimethylammonium) propyl] chitosan chloride (HTCC) can protect the insulin analog from the cross-linking reaction and maintain its activity. The positive charged chitosan microspheres also showed improved bioadhesion to the intestinal tract due to a strong interaction with the mucus. Evaluation using an in vivo diabetic model showed an optimal reduction in blood glucose level and compelling therapeutic effects after treatment with insulin analog loaded chitosan microspheres, which further confirmed the feasibility of using quaternized chitosan microspheres as insulin carriers for oral administration [156].

In case of oral drug delivery, the use of microspheres loaded with antibiotics would be beneficial for several diseases [157]. A particular problem related to a low molecular weight compound like ampicillin is the high permeability of the chitosan microbead matrix material. In order to overcome these restrictions, chitosan gel beads and microspheres are generally crosslinked chemically using glutaraldehyde or ethylene glycol diglycidyl ether [157]. However, residual glutaraldehyde and ethylene glycol diglycidyl ether in the chitosan microspheres give rise to health concerns and can cause undesirable effects including irritation to mucosal membranes. To solve these disadvantages of chemical crosslinking, researchers have proposed to apply chitosan microspheres reacetylated with acetic anhydride. The reacetylated chitosan microspheres were able to interact closely with the gastric mucosa and to exhibit sustained delivery of entrapped antibiotic [158].

The factors affecting drug encapsulation efficiency, particle size, surface charge, surface hydrophilicity, pharmacokinetics and biodistribution were studied in clozapine-loaded nanoparticles coated with chitosan, pluronic F-68, polyethylene glycol (PEG) 4000 and polysorbate 80 . The results proved that although a similarity in surface hydrophilicity, chitosan-stealth nanoparticles showed different pharmacokinetic profile and biodistribution behavior compared to polysorbate-stealth nanoparticles [159]. A great improvement in surface hydrophilicity was brought by chitosan and polysorbate 80 coatings. However, the in vivo 
particle uptake by the reticuloendothelial system was less pronounced with positively charged chitosan-stealth nanoparticles than with polysorbate 80. In another study, the thermal amide conjugation of COO- group of EDTA with $\mathrm{NH}_{2}$ group of chitosan was employed to prepare microparticles, which showed higher amphotericin B loading capacity, enhancement in the in vitro dissolution performance 12 -fold and a nanoemulsion was produced in the size range of 70-90 nm [160]. On the other hand, microparticles were prepared entrapping ovalbumin as a model antigen following oral vaccination. In another investigation, methylated $\mathrm{N}-(4-\mathrm{N}, \mathrm{N}-$ dimethylaminocinnamyl) chitosan was used to coat microparticles, which demonstrated a greater swelling, mucoadhesive properties and a more sustained release than uncoated microparticles. Thus, this formulation represent a useful carrier to improve the immunogenicity of oral vaccines [161].

Galactosylated trimethyl chitosan-cysteine nanoparticles were developed for oral delivery of a mitogen-activated protein kinase kinase kinase kinase 4, siRNA to the activated macrophages. This formulation was effective in protecting mice from dextran sulfate sodium induced ulcerative colitis at a relatively low therapeutic dose by attenuating colonic TNF- $\alpha$ production. Aditionally, a stability enhanced, cell binding and cellular uptake in activated macrophages, low cytotoxicity, high transfection efficiency in vitro, and direct delivery to the focus of disease were showed [162].

\subsection{Buccal drug delivery}

The buccal route is an alternative choice to deliver drugs to the application site. In addition, this route shows high acceptance by patients. An ideal buccal delivery system should stay in the oral cavity for hours and release the drug in a controlled way. Mucoadhesive polymers prolong the residence time of the drug in the oral cavity [163]. Based on its mucoadhesive as well as absorption enhancement properties, chitosan is a promising polymer to be used for buccal delivery, such as chitosan mixed with sodium alginate, which was studied as a vehicle in buccal tablets; while chitosan glutamate, interacted with polycarbophil and other anionic polymers and was proposed for bilaminated films and bilayered tablets [164, 165].

Chitosan salts have different physical properties and can have different effects on mucosa permeability [166, 167]. A combination of chitosan and Pluronic F-127 was investigated in one study, showing that the drug release systems for via buccal was improved and demonstrating that independently of chitosan salt type (citrate, acetate and lactate), mucoadhesion was significantly favoured when the concentration of Pluronic F-127 in the matrix was about 30\% $(\mathrm{w} / \mathrm{w})$. Chitosan lactate gave good sustained release, controlled swelling, and higher mucoadhesion when combined with Pluronic F-127 present in the matrix at the above concentration (Figure 3). These results indicate that such a matrix could find useful application in buccal drug delivery systems [168]. 


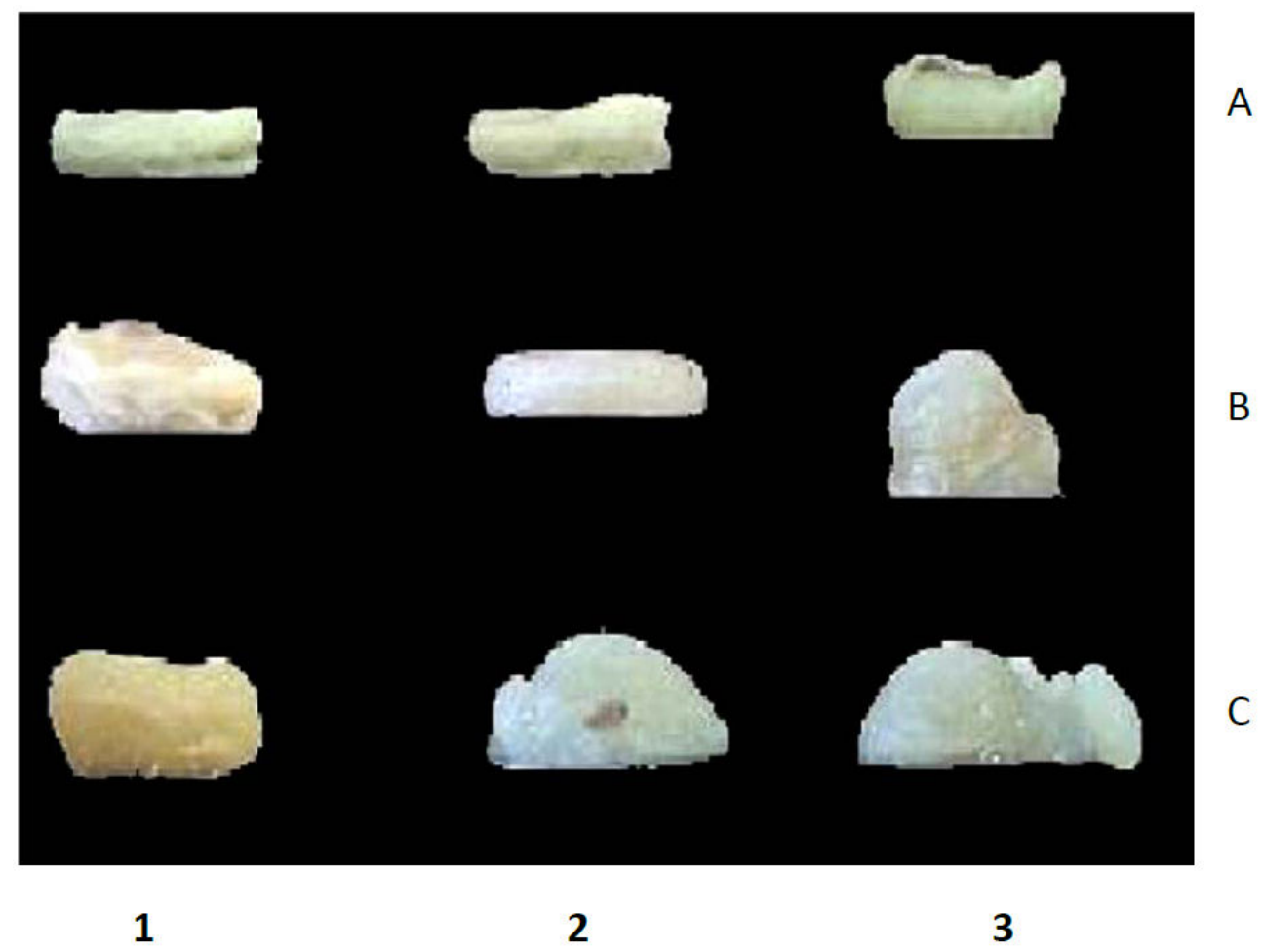

Figure 3. Pictures of swollen matrices, containing different chitosan salt type (1-chitosan acetate; 2 -chitosan citrate; 3 -chitosan lactate) and different amounts of P407 [A-at about 50\% (w/w); B-at about 30\% (w/w); C-at about $12 \%(\mathrm{w} / \mathrm{w})]$. The images were taken $4 \mathrm{~h}$ after starting the swelling study. This figure is reproduced with the permission [168].

Other modifications such as, trimethylated chitosans seem to be promising exipients for drug delivery systems intended for buccal mucosa applications to enhance the absorption of hydrophilic macromolecules [169]. In another study, the potential of thiolated chitosan for peptide delivery systems via the buccal mucosa was investigated in pigs [170]. The therapeutic peptide PACAP was applied to pigs, and its bioavailability was determined in order to facilitate the treatment of type 2 diabetes. Due to its strong permeation enhancing properties, tablets based on thiolated chitosan raised continuously the plasma level of this peptide drug, allowing for therapeutic range levels to be maintained over the whole period of application. Furthermore, buccal bilayered devices with a mixture of nifedipine and propranolol as well as chitosan displayed promising potential for use in controlled delivery in the oral cavity [171].

Chitosan (derivatives) can interact with mucus and epithelial cells and induced a redistribution of cytoskeletal F-actin and the tight junction protein ZO-1 resulting in opening of cellular tight junctions and increasing the paracellular permeability of the epithelium [172, 173]. Besides their charge, other structural elements of these polymers likely contribute to their penetration- 
enhancing activity, since cationic polysaccharides such as quaternized diethyl aminoethyldextran were ineffective as an enhancer.

\subsection{Colon drug delivery}

Colon specific drug delivery systems are gaining importance for use in the treatment of chronic diseases, such as irritable bowel syndrome, inflammatory bowel disease, ulcerative colitis, and also for the systemic delivery of protein and peptide drugs. By making use of this colon-specific degradation, chitosan has been discovered as useful coating in order to guarantee a site specific delivery. Radiolabelled $(99 \mathrm{mTc})$ tablets coated with a combination of pectin/chitosan/hydroxypropyl methylcellulose $(3+1+1)$, for instance, were administered orally to human volunteers [174]. Within this study, gamma scintigraphy was used to evaluate the gastrointestinal transit of these tablets, showing that they remain intact through the stomach and small intestine. In the colon, the bacteria degraded the coat, and thus, the tablets disintegrated. In another study, it was developed a sustained dosage form for alpha-lipoic acid making use of ionic interactions between this anionic drug and chitosan used as carrier matrix. Studies in human volunteers showed a release maximum once the formulation had reached the colon [175].

Chitosan hydrogel beads coated with enteric polymer Eudragit S 100 were also investigated to be targeted to the colon; they prevented premature drug release in simulated gastric fluid, but delivered in the colon, because chitosan was degraded by the bacterial enzymes. Prednisolone, 5-aminosalicyclic acid, metronidazole, 5-fluorouracil and indomethacin are being investigated in chitosan formulations for the same purposes [176].

Mixes are being used to obtain some characteristics on the formulations. Here, blended chitosan with gelatin was used to improve the biological activity since (i) gelatin contains ArgGly-Asp (RGD)-like sequence that promotes cell adhesion and migration, and (ii) forms a polyelectrolyte complex [177]. Addition of gelatin affected the stiffness of 2D and 3D scaffolds, facilitated the degradation rate and maintained the dimension in the presence of lysozyme. The effect of blending chitosan with poly( $\varepsilon$-caprolactone) (PCL) also improved mechanical properties as well as cellular support [178]. The $\gamma$-poly (glutamic acid), a hydrophilic and biodegradable polymer, was also used to modify chitosan matrices and the $\gamma$-poly (glutamic acid)/chitosan composite matrix was found to enhance hydrophilicity and serum proteins adsorption, and to increase the maximum strength through addition of $\gamma$-poly (glutamic acid) in tissue engineering applications [179]. The mechanical properties and biocompatibility also were improved with galactosylated chitosan-based scaffolds by combining them with alginate. The scaffolds exhibited the usual pore configurations, and the pore sizes were dependent on the freezing pre-treatments, the molecular weight of chitosan and amount of galactosylated chitosan $[180,181]$.

\subsection{Pulmonary drug delivery}

Powder formulations of protein-loaded chitosan nanoparticles suitable for pulmonary delivery have been prepared by spray drying [182-184]. Moreover, insulin-loaded nanoparticles chitosan have been reported obtaining a good loading capacity (65-80\%) and were fully 
recovered from the powder formulations after contact with an aqueous medium, and showed a fast release of insulin. The biocompatibility and penetration-enhancing effects of their chitosan powder formulations were examined in vitro using A549 and Calu-3 cells as models for alveolar and respiratory epithelial cells, respectively [185]. The formulations exhibited a very low cytotoxicity in both cell lines, but no effects on opening of tight junctions of the cells were reported. Further, CLSM studies did not reveal internalization of nanoparticles which contrasts previously reported studies [183]. The authors speculated that the total amount of chitosan used in their study was lower than that used in other publications. Moreover, the chitosan salt (glutamate) probably did not lose its charge after dispersing the particles in buffer [183].

An inhalable chitosan-based powder formulation of salmon calcitonin-containing mannitol as a cryoprotecting agent using a spray drying process was prepared. The effect of chitosan on the physicochemical stability of the protein was examined with chromatographic and spectrometric techniques [186]. The dissolution rate of the protein decreased when it was formulated with chitosan, which might be due to an irreversible complex formation between the protein and chitosan during the drying process [183]. On the other hand, chitosan-coated PLGA nanoparticle suspensions improved the absorption of calcitonin after pulmonary administration aerosolized with a nebulizer. The elimination of the chitosan-coated nanoparticles from the lungs was retarded as compared to non-coated particles, most likely due to the mucoadhesive properties of chitosan. It was shown that after pulmonary administration of the chitosan-coated particles the pharmacological action of calcitonin was prolonged as compared to that of the protein loaded in the non-coated nanoparticles [187]. In another study, the potential of chitosan oligomers and polymers for pulmonary delivery of proteins was studied. The absorption of interferon- $\alpha$ in rats was improved after pulmonary administration of aqueous solutions of the oligomers and the interferon- $\alpha$. Among various oligomers, glucoseamine hexamers at a concentration of $0.5 \%(\mathrm{w} / \mathrm{v})$ showed the highest efficacy. Chitosan polymers were less efficient than the studied oligomers in increasing the systemic level of the interferon- $\alpha$, likely due to their lower solubility in lung fluids [188].

Interesting results were obtained with $\mathrm{N}$-trimethyl chitosan powder formulations of insulin using a drying process for pulmonary delivery [189]. The particles had an average volume aerodynamic diameter of $4 \mu \mathrm{m}$ suitable for peripherally pulmonary deposition. After one-year storage at $4{ }^{\circ} \mathrm{C}$, the particle characteristics were maintained and the insulin structure was largely preserved [189]. Pulmonary administration of N-trimethyl chitosan-insulin microparticles significantly enhanced the systemic absorption of insulin, with a bioavailability of about $95 \%$ relative to subcutaneously administered insulin.

It has been studied the development of a novel nanocarrier consisting of Lipoid S100 and chitosan or glycol-chitosan for the systemic delivery of low molecular weight heparin upon pulmonary administration. These nanosystems, formed by ionic gelation technique, provided both sufficient entrapment efficiency and mucoadhesive properties. Aerosolization of these formulations indicated that heparin could be delivered to the lung. Overall, these nanocarriers might have a use potential for systemic delivery of low molecular weight heparin as compared to free drug with a therapeutic potencial effect for the treatment of pulmonary embolism and 
other thromboembolic disorders [190]. The potential to deliver ofloxacin directly to alveolar macrophages via the respiratory route was enhanced from loaded glutaraldehyde-crosslinked chitosan microspheres in comparison with the ofloxacin powder. It suggests that chitosan microspheres are efficient delivery system of ofloxacin to cure tuberculosis [191].

\subsection{Intranasal drug delivery}

Chitosan-coated gold nanoparticles have been investigated for mucosal protein delivery [192]. Chitosan was used as a reducing agent in the synthesis of gold nanoparticles and also as a mucoadhesive and penetration enhancer. Insulin was efficiently adsorbed ( $~ 50 \%)$ through electrostatic interaction onto the surface of the coated nanoparticles and they were colloidally stable for 6 months. Intranasal administration of these nanoparticles in diabetic rats showed an improved pharmacodynamic effect as evidenced by higher reduction in blood glucose levels as compared to insulin-loaded sodium borohydride gold nanoparticles [192].

In another study nanoparticles consisting of chitosan and negatively charged cyclodextrin sulfobutylether- $\beta-C D$ or carboxymethyl- $\beta-C D$ derivatives were prepared and characterized [104]. It was demonstrated that chitosan-sulfobutylether- $\beta$-CD-insulin nanoparticles induced lower TEER values of Calu-3 cells than chitosan-carboxymethyl- $\beta-C D-i n s u l i n$ nanoparticles. However, both insulin-loaded nanoparticles showed similar effects on reduction of rats' plasma glucose levels upon intranasal administrations. It should be noted that, the plasma insulin concentrations of the treated animals which may give better indications in absorption enhancement properties of the formulations, were not determined [104]. Chitosan has been investigated as auxiliary agent in nasal drug delivery systems [193] due to mucoadhesive properties improving significantly nasal uptake of isosorbide dinitrate due to the co-administration of chitosan in rats [194]. In the same study, they showed a minor cilio-inhibiting effect of the polymer. In addition, fentanyl nasal spray formulations with pectin, chitosan, and chitosan-poloxamer 188 were developed for clinical evaluation to provide rapid absorption and subsequently increased bioavailability. The study was conducted in 18 healthy adult volunteers and revealed significantly increased systemic exposure as well as reduced times to peak plasma values for all formulations compared with oral transmucosal fentanyl citrate lozenge [195].

Recently, formulations prepared with chitosan and Pluronic F-127 as nasal delivery vehicles of vaccines have been reported [116, 196, 197]. In a study, some mice Balb/c mice were intranasally immunized with the antigen tetanus toxoid in the presence of chitosan, Pluronic F-127/chitosan or lysophosphatidylcholine (LPC) showing that the antigen specific IgA response in the nasal and lung washes of these animals had a significant increase in antitetanus toxoid mucosal IgA response in the group of mice immunized and boosted intranasally with Pluronic F-127/chitosan, enhancing the systemic and mucosal immune responses compared with those in the control groups. Successful mucosal vaccination is therefore largely dependent on the development of effective mucosal adjuvants. As it is well known, the adaptive humoral immune defense at the mucosa is mediated by the antibodies IgA that in mucosal secretions binds to the microbes and toxins present in the lumen and neutralize them by blocking their entry into the host [198, 199]. This nasal vaccine could induce not only 
systemic IgG antibody responses but also mucosal IgA antibody responses, which results in two layers of immune defense against infectious diseases. So, this study showed that the system represents a novel nasal vaccine delivery system to enhance immune response [200]. Important effects in the nasal delivery of vaccines were found, when the Bordetella bronchiseptica antigen was included in the chitosan microspheres prepared with Pluronic F-127, which was used as a stabilizing and immunomodulating agent [115]. In the in-vitro release study, a greater amount of the antigen was released from the chitosan microspheres prepared in the presence of Pluronic F-127 than from only chitosan microspheres, due to the hydrophilic property of poloxamer. The mice intranasally immunized with the microspheres using Pluronic F-127, showed higher IgA antibody titers against the antigen in their mucosal secretions (nasal washes and saliva) than the mice intranasally immunized with microspheres containing only the antigen. This study suggested that chitosan microspheres prepared in the presence of Pluronic F-127, could enhance the nasal delivery of a variety of clinically useful antigens in vaccination schemes. Besides the enhanced immune responses, advantages of this system include the easy preparation method, which only involved simple mixing by the ionic gelation method with tripolyphosphate or by the emulsion-crosslinking method employing glutaraldehyde avoiding extreme conditions such as heating and organic solvent which might result in the denaturation of protein antigens [115, 201].

Another objective was obtained with leucine-enkephalin loaded N-trimethyl chitosan nanoparticles, which were evaluated as a brain delivery vehicle via nasal route and prepared by ionic gelation method. The permeability of Leucine-enkephalin released from nanoparticles was 35 fold improved from the nasal mucosa as compared to Leucine-enkephalin solution. Fluorescent microscopy studies of brain sections of mice showed higher accumulation of fluorescent marker NBD-F labelled Leucine-enkephalin, when administered nasally by $\mathrm{N}$-trimethyl chitosan nanoparticles, while low brain uptake of marker solution was observed. It was conclude that $\mathrm{N}$-trimethyl chitosan nanoparticles could generate a significant improvement of bioactive Leucine-enkephalin levels in the brain when is intranasally administered [203].

\subsection{Ocular drug delivery}

Chitosan is a suitable material for the design of ocular drug delivery systems due to its nontoxic character, permeation enhancing properties, and physicochemical characteristics. Chitosanbased formulations used for ophthalmic drug delivery are hydrogels [203], nanoparticles [127], and coated colloidal systems [204]. Chitosan as well as Pluronic F-127, has recently been proposed as a material with a good potential for ocular drug delivery, since their solutions were found to prolong the corneal residence time of antibiotic drugs and nanocapsules coated with chitosan were more efficient to enhance the intraocular penetration of some specific drugs [205]. Making use of their in situ gelling properties, the formulations can be applied and distributed on the ocular surface in almost liquid form thereafter transforming into the gel status [203]. A combination of polycaprolactone nanocapsules as ocular carriers with the advantages of the cationic mucoadhesive chitosan and poly-L-lysine as coating was performed. Even though poly-L-lysine and chitosan displayed a similar positive surface charge, 
only chitosan-coated nanocapsules enhanced the ocular penetration of indomethacin with respect to uncoated nanocapsules. The authors suggested that an undetermined property of chitosan was responsible for this enhanced uptake [204].

In other studies chitosan-alginato microspheres or beads were investigated for the encapsulation of several drugs, proteins, cells and oligonucleotides, with promising results [206-211]. The complex has biocompatible and biodegradable characteristics, and limits the release of encapsulated materials more effectively than either alginate or chitosan alone [212]. A further advantage of this delivery system is its non-toxicity permitting the repeated administration of therapeutic agents. In another study, chitosan-sodium alginate nanoparticles entrapping gatifloxacin (a broad-spectrum antibacterial agent used in the treatment of ocular infections) were successfully formulated. The results showed that the drug was released over a period of 24 hours in a sustained release manner, primarily by non-Fickian diffusion. This new formulation is a viable alternative to conventional eye drops by virtue of its ability to sustain the drug release, for its ease of administration because of reduced dosing frequency resulting in better patient compliance [213].

\subsection{Topical/transdermal delivery systems}

Some mixes of polymers using chitosan could be used to prepare thermosensitive hydrogels which were a good choice to reduce local irritation in the skin caused by conventional transdermal patches ( $40 \%$ of application-site skin reaction) due to components of the patch (acrylic adhesive, polyester, polyurethane, and silicone). Therefore, these formulations can also provide advantages for particular applications as it is transformed from a liquid to a gel when administered topically [214]. Additionally, modifications in the delivery of drugs could be achieved, such as that obtained for a hydrogel patch composed of chitosan and starch developed for cosmetic applications, in which a rapid curcumin release rate was observed [215].

\subsection{Regenerative systems}

Amino acid grafted chitosans posses a great potential for application in these biomedical fields, whereby a combination of the properties of chitosan and those belonging to different amino acid moieties could produce materials with synergetic properties. Moreover, this conjugation can enhance some properties of chitosan, such as its antimicrobial activity, which are important in the area of tissue engineering such as wound healing [216]. Many tissue analogs including cartilage, bone, liver, and nerve have been prepared using this engineering technology. Systems of blood clots based in chitosan-glycerol phosphate disodium salt were purposed since bleeding has been identified as an initiating event in post-surgical repair and it was hypothesized that microfracture-based repair could be improved by stabilizing the clot formed in the lesion with chitosan that is thrombogenic and actively stimulates the wound-healing process [217]. These systems were applied as implants to marrow-stimulated chondral defects in rabbit cartilage repair models, where they induced greater fill of chondral defects with repair of tissue compared to marrow-stimulation alone [218]. In another investigation, a chitosanhydroxyapatite multilayer nanocomposite with high strength and bending modulus rendering the material suitable was prepared for possible application as an internal fixation of long bone 
fractures [219]. A series of chitosan-tricalcium phosphate composite scaffolds were developed for the same purpose using freeze-drying process, which provided macroporous composite scaffolds with different pore structures. The biocompatibility, evaluated subcutaneously on rabbits indicated that these scaffolds can be utilized in non-loading bone regeneration [220]. The use of biomimetic hydroxyapatite/chitosan-gelatin network composites in the form of 3Dporous scaffolds improved adhesion, proliferation and expression of rat calvaria osteoblasts on these systems [221]. Recently, a scaffold with calcium phosphate cement and chitosan fibers with improved resistance to fatigue and fracture was used to harvest human umbilical cord mesenchymal stem cells without an invasive procedure that is commonly required when studying bone marrow mesenchymal stem cells. This system had flexural strength of $26 \mathrm{MPa}$, while calcium phosphate cement control was $10 \mathrm{MPa}$. In addition, an excellent and higher viability of human umbilical cord mesenchymal stem cells was obtained with scaffolds using chitosan fibers than those controls without fibers. Human umbilical cord mesenchymal stem cells had excellent proliferation (300 and 700 cells $/ \mathrm{mm}^{2}$ on 1 and 4 day, respectively) and viability on the scaffolds [222]. A study showed that the chitosan surface modified with fructose (ligand of asialo-glycoprotein receptor in hepatocyte) on porous chitosan scaffolds induced the formation of cellular aggregates and enhanced liver specific metabolic activities and cell density to a satisfactory level $[223,224]$. Chitosan microfibers were also developed and coated with collagen. Schwann and fibroblast cells were cultured on the chitosan microfibers to be adhered to the surface of the systems. After $72 \mathrm{~h}$, the Schwann cells had proliferated linearly while the fibroblast cells covered the surface of the chitosan microfibers. The chitosan microfibers provide very good scaffolds for many tissue engineering applications with the advantages of ease of fabrication, simplicity and cost effectiveness [225].

\section{Uptake and endocytic pathway of chitosan}

One of the most important routes to drug delivery is the oral pathway. The uptake of chitosan into the bloodstream is generally not investigated in oral administration studies. Chitosan's systemic absorption and distribution from this route of delivery may be largely dependent on the Mw. It is very likely that oligomers could show some absorption whereas larger $\mathrm{Mw}$ chitosans are excreted without being absorbed. This effect was seen with FITC-labeled chitosans with $3.8 \mathrm{kDa}$ ( $88.4 \%$ degree of deacetylation) chitosan having the greatest plasma concentration after oral administration vs $230 \mathrm{kDa}(84.9 \%$ degree of deacetylation) having almost no uptake. Increasing Mw was seen to decrease the plasma concentration in this, one of the only studies investigating plasma concentration after oral administration [226]. Trimethyl chitosan oligomers/DNA nanoparticles were taken up in the gastric and duodenal mucosa and to some extent in the jejunum mucosa, ileal mucosa and large intestinal mucosal cells as shown by green fluorescent protein (GFP) expression [227]. Chitosan polymers are not absorbed by the gastrointestinal way and are unlikely to show biodistribution. Chitosan oligosaccharides however may be absorbed to some extent.

Although native chitosan has not been investigated, the intracellular uptake and distribution of chitosan/DNA complexes have been studied in vitro [228-230]. Chitosan polyplex uptake 
at $37^{\circ} \mathrm{C}$ was 3 -fold higher than at $4{ }^{\circ} \mathrm{C}[228]$ but this could be due to increased interaction and not an ATP dependent endocytic mechanism. The authors suggested nuclear localization and they also stated little dissociation of the DNA from the chitosan. In a more comprehensive study, Leong et al. stained for lysosomes and found some co-localization with chitosan DNA nanoparticles. However, the majority of the polyplexes were found in the cytosol [229]. A complex of doxorubicin with chitosan has also been studied; complexes enter cells through an endocytic mechanism which was not further elucidated [231]. Hydrophobic (5- $\beta$-cholanic acid) modified glycol chitosan nanoparticles were internalized into HeLa cells through all the endocytic mechanisms studied: clathrin coated vesicles, caveolae and macropinocytosis. This study agrees with that of Leong, in that some particles were lysosomal but most were not [232]. Unfortunately, these studies all involve nanoparticle uptake of relatively large (>100 nm) nanoparticles or aggregates of complexes and not just labeled chitosan. Dodane and Vilivalem reported that chitosan has membrane perturbing properties that do not decrease cell viability [233]. It is likely that chitosan and chitosan nanoparticles enter the cell via cell membrane perturbation due to the cationic charge. It is important to understand chitosan's cell trafficking and investigate both endocytosis and exocytosis. Such study should shed some light on chitosan's biocompatibility.

It is important to mention that cellular uptake kinetics may be altered due to the charge interaction (e. g. in the case of DNA complexes). This balancing, or reduction, of the positive charges on the chitosan molecule has effects on its interaction with cells and the microenvironment, often leading to decreased uptake and a decrease in toxicity. In the case of a covalent drug conjugate, the polymer's physicochemical properties (hydrophilicity) and conformation are altered (i. e. micelle formation) with a consequent effect on distribution and cell uptake [52]. Similar results were found for poly(dl-lactic-co-glycolic acid) nanospheres surface modified by adsorption of chitosan for pulmonary administration, which were preferentially taken up by human lung adenocarcinoma cells (A549) in a temperature dependent manner [234]. Moreover, cellular uptake of these nanocarriers increased with decreasing diameter to the submicron level and the cellular uptake of nanospheres were promoted through electrostatic interactions between the surface due to chitosan adsorbed and the negatively charged cell membrane without showing cytotoxicity. Internalization of nanospheres (200-nm) by A549 cells appears to occur predominantly through adsorptive endocytosis initiated by nonspecific interactions between nanospheres and cell membranes, and is partially mediated by a clathrinmediated process. Thus, chitosan is suitable as a material for surface modification of systems for intracellular targeting because it could increase the interaction between the cell membrane and the systems [234]. The effect on the charge of the systems was also reported for a large array of N-(2-hydroxypropyl)methacrylamide (HPMA) based copolymers, which were internalized into the prostate cancer cells through multiple endocytic pathways: positively charged copolymers robustly engaged clathrin-mediated endocytosis, macropinocytosis and dynamin-dependent endocytosis, while weakly negatively charged copolymers weakly employed these pathways; strongly negatively charged copolymers only mobilized macropinocytosis [235]. 
The hydrophobicity of the systems as drug delivery vehicles for therapeutic applications is another physicochemical property which has been investigated on the cellular uptake. Here, a hydrophobic glycol chitosan system ( $5 \beta$-cholanic-acid conjugated glycol chitosan) was reported to show several distinct uptake pathways involved in their internalization with a single degree of substitution [232]. Moreover, different degree of substitution (or hydrophobicity) could affect the endocytosis of hydrophobically-modified polymers. The cellular uptake of nanoparticles prepared by a hydrophobically-modified chitosan (N-palmitoyl chitosan), was significantly enhanced with increasing the degree of substitution. The internalization of these systems was clearly related with the lipid raft-mediated routes. With increasing the hydrophobicity on polymer, the caveolae-mediated endocytosis became more important. The internalized nanoparticles transiently associate with CAV1 at cell membranes and at a peripheral CAV1- positive structure coupled with caveosomes before trafficking to the endosomal pathway [236].

In addition, the cell entry and subsequent intracellular trafficking of drug carriers using chitosan or a combination with another polymer are strongly dependent on their physicochemical characteristics, such as charge and molecular weight. In addition, the route of administration determines the uptake, concentration, contact time and cell types affected [52].

\section{Advantages and limitations over other pharmaceutical systems for non parenteral routes}

\subsection{Advantages}

Chitosan is one of the most promising polymers because of its nontoxic, polycationic, biocompatible, and biodegradable nature and particularly due to its mucoadhesive and permeation-enhancing properties [237-239]. Moreover, the strong mucoadhesive property of chitosan is most important for drug delivery through the mucosal routes. In addition, the interaction of the positively charged chitosan with the negatively charged mucin layer and the tight junctions facilitates the paracellular transport of hydrophilic macromolecules by opening the tight junctions of the mucosal barriers [111, 239-242]. Additionally, chitosan is cheap [243]. Practical use of chitosan has been widely investigated due to its ability to form hydrogels, to its biocompatibility in physiological environments (enzymes chitosanase and lysozyme degrade chitosan and form harmless products), enhancing it with deacetylation reactions. Moreover, its biocompatibility was demonstrated with viable cartilage producing any untoward effect [216].

One of many investigations using chitosan is as vaccines vehicles, which have showed better efficacy than the approved injectables (induce strong systemic immune responses and represent a pharmaceutical form painful). Diverse chitosan microspheres have been evaluated for controlled drug release and to enhance the protection and permeation of the antigens in the nasal mucosa, inducing antigen specific immune responses in both the nasal mucosa and the systemic compartment $[114,115,196,197]$. Besides, the induction site of the antigen-specific 
mucosal immune responses were found contained in a broad range of mucosal surfaces (nasal and vaginal routes and the salivary gland).

Several studies have been conducted on chemically modified chitosan systems through their concomitant use with adjuvants for a synergistic effect, and through the mannosylation of chitosan for target the receptor-mediated. The chemically modified chitosan systems combined with other adjuvants have showed to have an increased immunostimulatory in nasal vaccine delivery $[114,115]$. Another advantage of chitosan formulations is its cationic property, which has been also exploited to deliver a tissue plasminogen activator to substrates of the fibrin network or insulin to mucosa surfaces [244, 245]. Nasal delivery of insulin from solutions and gels based of chitosan incremented greatly the permeability and transmucosal absorption, which could avoid the pain and inconvenience of injections of insulin in patients [246, 247). Moreover, in vitro insulin delivery using gels of chitosan, glutaraldehyde, Pluronic F-127/F-68 and glycine significantly reduced the burst release of insulin and sustained the release of it for up to $20 \mathrm{~h}$, suggesting that such gels are potentially effective carriers of insulin for nasal delivery [247].

Systems based in chitosan can provide advantages by their mucoadhesive properties overcome to the conventional formulations such as those for via ophthalmic, that are eliminated from the precorneal area immediately upon instillation because of lacrimal secretion and nasolacrimal drainage, needing a frequent instillation of concentrated solutions to achieve the desired therapeutic effects [248, 249]. In order to lengthen the resident time of instilled dose and enhance the ophthalmic bioavailability various conventional and non conventional (colloidal drug delivery systems, such as liposomes, biodegradable nanoparticles and nanocapsules) ophthalmic vehicles based in chitosan have been developed, but their use is reduced due to some adverse effects such as blurred vision from ointment or low patient compliance from inserts [250]. In order to avoid the blurred vision, a combination of chitosan and Pluronic F-127 could be used for the preparation of in situ forming gels with improved mechanical and mucoadhesive characteristics for prolonged precorneal residence time in vivo [251].

Mucoadhesive properties are also important for the buccal administration, which involve the direct entry of the drug into the systemic circulation avoiding the first pass hepatic metabolism. This route is easily accessible for self medication where the drug can be easily administered or if necessary, removed from the site of application. In order to maintain the device in its position for many hours against buccal motion and salivary flow, which could reduce the mucosal absorption, the dosage form must have good adhesive properties and show an efficient control of drug delivery. These characteristics have been obtained with systems using chitosan alone, modified chitosan, chitosan mixed with other components such as, sodium alginate or using chitosan glutamate proposed for bilaminated films and bilayered tablets [117, $118,164]$. In adittion, chitosan has the potential to be a safe pharmaceutical excipient for nonparenteral drugs. Altohoug it was approved for dietary applications in Japan, Italy and Finland and it has been approved by the FDA for use in wound dressings, more studies must be performance to ensure its safety. In Table 6 summarizes mains advantages in applications of chitosan systems by use other components. 


\begin{tabular}{|c|c|c|}
\hline Materials & Applications & References \\
\hline Chitosan and carmomer & Improved oral bioavailability of buserelin. & [141] \\
\hline Chitosan and PEGylated & 3. 4-fold was improved its mucoadhesive properties of chitosan. & {$[142]$} \\
\hline $\begin{array}{l}\text { Preactivation of thiol groups on chitosan via the } \\
\text { formation of disulfide bonds with } \\
\text { mercaptonicotinamide }\end{array}$ & $\begin{array}{l}\text { Mucoadhesive properties of thiolated chitosans were even significantly } \\
\text { improved. }\end{array}$ & [143] \\
\hline $\begin{array}{l}\text { Chitosan and poly(g-glutamic acid) and chitosan } \\
\text { and polyacrylic acids }\end{array}$ & $\begin{array}{l}\text { This combination could be infiltrated in the cell-cell junctions and interact } \\
\text { with Helicobacter pylori infection sites for the treatment of peptic ulcer. }\end{array}$ & [252] \\
\hline $\begin{array}{l}\text { Modified chitosan hydrogels loaded with } \\
\text { metronidazole, tetracycline and theophylline }\end{array}$ & $\begin{array}{l}\text { Modified chitosan hydrogels loaded with metronidazole, tetracycline and } \\
\text { theophylline could bypass the acidic environment of the stomach and } \\
\text { release the loaded drug into the intestine }\end{array}$ & [252] \\
\hline Chitosan and thiolated chitosan & $\begin{array}{l}\text { Chitosan and thiolated chitosan are used to improve the oral bioavailability } \\
\text { of acyclovir } 3 \text {-fold and } 4 \text {-fold. }\end{array}$ & [148] \\
\hline $\begin{array}{l}\text { Chitosan with glutaraldehyde or ethylene glycol } \\
\text { diglycidyl }\end{array}$ & $\begin{array}{l}\text { Chitosan with glutaraldehyde or ethylene glycol diglycidyl are used to load } \\
\text { antibiotics. }\end{array}$ & [174] \\
\hline $\begin{array}{l}\text { Chitosan microspheres reacetylated with acetic } \\
\text { anhydride }\end{array}$ & $\begin{array}{l}\text { The re-acetylated chitosan microspheres were able to interact closely with } \\
\text { the gastric mucosa and to exhibit sustained delivery of entrapped antibiotic }\end{array}$ & {$[175]$} \\
\hline $\begin{array}{l}\text { Clozapine-loaded nanoparticles with chitosan } \\
\text { and polysorbate } 80\end{array}$ & $\begin{array}{l}\text { A great improvement in surface hydrophilicity was brought by chitosan and } \\
\text { polysorbate } 80 \text { coatings }\end{array}$ & {$[176]$} \\
\hline $\begin{array}{l}\text { Pectin/chitosan/hydroxypropyl methylcellulose } \\
(3: 1: 1)\end{array}$ & This formulation had reached the colon & [174] \\
\hline Chitosan and pluronic F-127 & $\begin{array}{l}\text { Drug release systems for via buccal was improved and demonstrating that } \\
\text { independently of chitosan salt type (citrate, acetate and lactate), } \\
\text { mucoadhesion was significantly favoured when the concentration of } \\
\text { Pluronic F-127 in the matrix was about } 30 \%(\mathrm{w} / \mathrm{w}) \text {. }\end{array}$ & [175] \\
\hline Trimethylated chitosans & $\begin{array}{l}\text { Sandri et al. (2005) showed that trimethylated chitosans seem to be } \\
\text { promising exipients for drug delivery systems intended for buccal mucosa } \\
\text { applications to enhance the absorption of hydrophilic macromolecules. }\end{array}$ & [169] \\
\hline $\begin{array}{l}\text { Chitosan hydrogel beads coated with enteric } \\
\text { polymer Eudragit S } 100\end{array}$ & $\begin{array}{l}\text { Chitosan hydrogel beads coated with enteric polymer Eudragit } \mathrm{S} 100 \text { to be } \\
\text { targeted to the colon, prevented premature drug release in simulated } \\
\text { gastric fluid, but delivered in the colon, because chitosan was degraded by } \\
\text { the bacterial enzymes. }\end{array}$ & [159] \\
\hline Chitosan with gelatin & $\begin{array}{l}\text { Huang et al. (2005) blended chitosan with gelatin to improve the biological } \\
\text { activity. }\end{array}$ & [177] \\
\hline Chitosan with poly( $\varepsilon$-caprolactone) & $\begin{array}{l}\text { These blending membranes improved mechanical properties as well as } \\
\text { cellular support. }\end{array}$ & [178] \\
\hline $\begin{array}{l}\text { The } \gamma \text {-poly (glutamic acid) ( } \gamma \text {-PGA) a hydrophilic } \\
\text { and biodegradable polymer }\end{array}$ & $\begin{array}{l}\text { This formulation was also used to modify chitosan matrices and the } \gamma^{-P G A /} \\
\text { chitosan composite matrix was found to enhance hydrophilicity and serum } \\
\text { proteins adsorption, and to increase the maximum strength through } \\
\text { addition of } \gamma \text {-PGA in tissue engineering applications. }\end{array}$ & [179] \\
\hline Chitosan and PLGA & $\begin{array}{l}\text { Yamamoto et al. showed that chitosan-coated PLGA nanoparticle } \\
\text { suspensions improved the absorption of calcitonin after pulmonary } \\
\text { administration. }\end{array}$ & [187] \\
\hline Chitosan-coated gold nanoparticles & $\begin{array}{l}\text { Chitosan-coated gold nanoparticles have been investigated for mucosal } \\
\text { protein delivery. }\end{array}$ & [253] \\
\hline Chitosan nanoparticles with cyclosporine A & $\begin{array}{l}\text { Chitosan nanoparticles with incorporated cyclosporine A in improving the } \\
\text { delivery of drugs to the ocular mucosa. }\end{array}$ & [127] \\
\hline
\end{tabular}

Table 6. Main advantages in applications of using of chitosan with different materials. 


\subsection{Disadvantages}

Several limitations of the systems using chitosan alone, modified chitosan, or chitosan mixed with other components could be mentioned. One of the most important is the general rapid clearance of the formulations in the mucosal surface owing to the mucociliary clearance and the presence of a variety of metabolic enzymes (cytochrome P-450 enzymes, conjugative Phase II enzymes, nonoxidative enzymes, and proteolytic enzymes that could reduce the absorption) of drugs administered via nasal using conventional chitosan formulations [254]. Nonetheless, these limitations are reduced when the drugs are entrapped in micro or nanoparticles using chitosan and other components.

Chitosan, has shown a hypoglycemic effect in streptozotocin (STZ)-induced diabetic animals [255- 257]. Other studies also found that low molecular weight chitosan (average MW about 2. $0 \times 10^{4} \mathrm{Da}$ ) as well as chitosan oligosaccharides can reduce plasma glucose level in diabetic animals [258,259]. On the other hand, when chitosan is used as a coat in liposomes, it helps in delaying intestinal transit time so as to increase absorption of insulin. An increase in chitosan molecular weight caused increase in the hypoglycemic efficacy of chitosan-coated insulin liposomes. The hypoglycemic efficacy of the liposomes coated by chitosan $1000 \mathrm{kDa}$ was markedly superior to that of the liposomes coated by other chitosans. Both increasing and decreasing chitosan concentration, the hypoglycemic efficacies of chitosan-coated insulin liposomes were decreased and the systems were not able to protect insulin from enzymatic digestion [260]. Thus, diabetic patients should be careful when administering chitosan if they not eating above.

Chitosan systems have limited applications in drug delivery and tissue engineering due to their hydrophilic nature and insolubility in certain physiological conditions (eg. blood-brain barrier), due to chitosan is soluble at $\mathrm{pH}$ values below 6.5 [261]. Besides its mucoadhesive and controlled release properties chitosan is also able to increase the paracellular permeability due to the opening of tight junctions which has been shown for various routes of delivery such as for nasal or intestinal drug delivery. However, no effect on the paracellular permeability could be observed at $\mathrm{pH} 7$. 4, which is the physiological $\mathrm{pH}$ of blood [262]. This indicates that chitosan solutions are not effective as permeation enhancer at neutral $\mathrm{pH}$ values, because of the missing solubility of chitosan at neutral and alkaline $\mathrm{pH}$ values. Chitosan in form of particles can overcome this problem, because particles need not to be dissolved.

It is important to mention that the modification of the polymer can change the properties of the systems. Chitosan can be readily modified by reactions at the amino and hydroxyl groups present in the molecule, but adequate optimizations of the formulations need to test, increasing costs, time, and toxicological studies. It is important to mention, that some derivatives increase in toxicity and any residual reactants must be carefully removed [51]. Additionaly, studies of in vivo and in vitro biodistribution and toxicity, using various chitosans of different molecular weights and degrees of deacetylation and derivatives would provide data that could help correlate chitosan's structure and safety profile [50]. Further studies needs to be conducted in this sense in order to approved based chitosan systems. 


\section{Conclusion}

Potential applications of chitosan as weight supplement in the market as well as drug carrier in pharmaceutical formulations and as an important material able to prepare regenerative structures for bones and cartilages have been investigated. Thus, this work summarizes recent pharmaceutical developments using chitosan, modified chitosan or mixes with other components as drug carriers for the most non parenteral routes of administration including oral, topical, intranasal, and ocular, etc. Various therapeutic agents, such as anticancer, antiinflammatory, antibiotics, antithrombotic, steroids, proteins, amino acids, antidiabetic and diuretics have been incorporated in chitosan-based systems as carriers to improve the dissolution rate of poorly soluble drugs and to achieve controlled release. Although, chitosan systems have limited applications in drug delivery and tissue engineering due to their hydrophilic nature and insolubility in certain physiological conditions (eg. blood-brain barrier) due to chitosan is soluble at $\mathrm{pH}$ values below 6.5 , chitosan particulate systems can be used as carriers for encapsulate drugs and to enhance their bioavailability and delivery. The primary amines of chitosan impart these valuable physicochemical properties including particular interactions with cells, proteins and living organisms. On the other hand, the safety of chitosan could also be achieved in shellfish allergic patients since it was shown that the subjects have tolerated the polymer without reaction demonstrating the safety of other chitin-derived products in patients allergic to shellfish. Since chitosan has the hydroxyl and amino functional groups, important results have been obtained by reacting chitosan with controlled amounts of multivalent anions (functional groups) to control hydrophobic, cationic and anionic properties enhancing the vectorization, the stability, and the mucoadhesively (to prolong the drug residence time) of the drug carrier systems. These properties of chitosan, especially their intrinsic antibacterial activity, their ability to bind anionic molecules such as growth factors, glucosamine glycans and DNA and their ability to be processed into a variety forms are also used to generate suitable structures for bone and cartilage regeneration. However, more studies to improve their mechanical properties are essential for this type of application. Although many successful systems of chitosan have been developed, more toxicity tests must be conducted in order to ensure their safety when it is incorporated in other systems.

\section{Acknowledgements}

The authors acknowledge a grant from UNAM (PAPIIT TA 200312 and PACIVE NCONS-17). The authors acknowledge the material provided with the Figures 2 and 3 in this work "Reprinted from European Journal of Pharmaceutical Sciences, 41(3-4), Günbeyaz, M., Faraji, A., Ozkul, A., Puralı, N., Senel, S., Chitosan based delivery systems for mucosal immunization against bovine herpesvirus 1 (BHV-1), Pages No 531-545., Copyright (2010)., and "Reprinted from Journal of Controlled Release, 102(1), Cafaggi, S. ; Leardi, R. ; Parodi, B. ; Caviglioli, G. ; Russo, E., Bignardi, G., Preparation and evaluation of a chitosan salt-poloxamer 407 based matrix for buccal drug delivery, Pages No 159-169., Copyright (2005)., with permission from Elsevier. 


\section{Author details}

Clara Luisa Domínguez-Delgado ${ }^{1}$, Isabel Marlen Rodríguez-Cruz², Enrique Fuentes-Prado ${ }^{3}$, José Juan Escobar-Chávez ${ }^{1}$, Gustavo Vidal-Romero ${ }^{4}$, Lorena García-González ${ }^{5}$ and Rafael Iván Puente-Lee ${ }^{6}$

*Address all correspondence to: clara_ldd@yahoo.com.mx

1 Multidisciplinary Research Unit, Laboratory 12 Transdermal Systems and Nanostructured Materials" Facultad de Estudios Superiores Cuautitlán-Universidad Nacional Autónoma de México (UNAM), San Sebastián Xhala, Cuautitlán Izcalli, Mexico

2 Teaching and Research Unit. Hospital Regional de Alta Especialidad de Zumpango, Zumpango, Mexico

3 Department of Engineering and Technology, Facultad de Estudios Superiores CuautitlánUniversidad Nacional Autónoma de México (UNAM), Mexico

4 Division of Graduate Studies (Pharmaceutical Technology), Facultad de Estudios Superiores Cuautitlán-Universidad Nacional Autónoma de México (UNAM), Mexico

5 Departament of Pharmacy, Facultad de Química-Universidad Nacional Autónoma de México (UNAM), Mexico

6 Departament of Chemical Engineering, Laboratory of Electronic Microscopy, Facultad de Química-Universidad Nacional Autónoma de México (UNAM), Mexico

\section{References}

[1] Kumar, M. N. V. R., Muzzarelli, R. A. A., Muzzarelli, C., Sashiwa, H., Domb, A. J. Chitosan chemistry and pharmaceutical perspectives. Chemical Reviews 2004; 104 6017-6084.

[2] Sonia, T. A., Sharma, C. P. Chitosan and its derivatives for drug delivery perspective. Advances in Polymer Science 2011; 243 23-54.

[3] Merzendofer, H. Chitin synthesis inhibitors: Old molecules and new developments. Insect Science. Article in Press DOI: 10. 1111/j. 1744-7917. 2012. 01535. x

[4] Khor, E. Chitin: Fulfilling a biomaterials promise. Elsevier Science: Amsterdam 2001.

[5] Dutta, P. K., Dutta, J., Tripathi, V. S. Chitin and chitosan: Chemistry, properties and applications. Journal of Scientific and Industrial Research 2004; 63 20-31. 
[6] Yeul, V. S., Rayalu, S. S. Unprecedented chitin and chitosan: A chemical overview. Journal of Polymers and the Environment 2012; In Press DOI: 10. 1007/ s10924-012-0458-x.

[7] Pearlmutter, N. L., Lembi, C. A. Localization of chitin in algal and fungal cell walls by light and electron microscopy. Journal of Histochemistry and Cytochemistry 1978; 26(10) 782-791.

[8] Rhazi, M., Desbriéres, J., Tolaimate, A., Alagui, A., Vottero, P. Investigation of different natural sources of chitin: influence of the source and deacetylation process on the physicochemical characteristics of chitosan. Polymer International 2000; 49(4) 337344

[9] Hwang, J. K., Shin, H. H. Rheological properties of chitosan solutions. Korea-Australia Rheology Journal 2000; 12(3-4) 175-179.

[10] Tabata, K., Koizumi, S. Increased production of nutriments by genetically engineered bacteria. In Bagchi, D., Lau, F. C., Ghosh, D. K. (eds. ) Biotechnology in Functional Foods and Nutraceuticals. Boca Raton: CRC Press 2010; 127- 137.

[11] Miranda-Castro, S. P., Lizárraga-Paulín, E. G. Is chitosan a new panacea? Areas of application. Chapter 1. In The complex world of polysaccharides. Karunaratne, D. N. Ed. ; InTech:, Croatia 2012; 5-46.

[12] Kasaai, M. R. Various methods for determination of the degree of N-acetylation of chitin and chitosan: A review. Journal of Agricultural and Food Chemistry 2009; 57 1667-1676.

[13] Franca, E. F., Freiras, L. C. G., Lins, R. D. Chitosan molecular structure as a function of n-acetylation. Biopolymers 2011; 95(7) 448-460.

[14] Green, J. H., Mattick, J. F. Fishery waste management. In: Green, J. H. ; Kramer, A. Eds. Food processing waste management. AVI publishing, Westport 1979; 202- 307.

[15] Il'ina, A. V., Varmalov, V. P. Chitosan-based polyelectrolyte complexes: A review. Applied Biochemistry and Microbiology 2005; 41(1) 5-11.

[16] Pillai, CKS., Paul, W., Sharma, CP. Chitin and chitosan polymers: Chemistry, solubility and fiber formation. Progress in Polymer Science 2009; 34(7) 641-678.

[17] Goycoolea, F. M., Fernández-Valle M. F., Aranaz, I., Heras, A., pH- and temperaturesensitive chitosan hydrogels: Swelling and MRI studies. Macromolecular Chemistry and Physics 2011; 212, 887-895.

[18] Zhou, H. Y., Chen, X. G., Kong, K., Liu, C. S., Cha, D. S., Kennedy, J. F. Effect of molecular weight and degree of chitosan deacetylation on the preparation and characteristics of chitosan thermosensitive hydrogel as a delivery system. Carbohydrate Polymers 2008; 73, 2, 265-273. 
[19] Zhang A. J., Qin Q. L., Zhang H., Wang H. T., Li X., Miao L., Wu Y. J. Preparation and characterization of food-grade chitosan from housefly larvae. Czech Journal of Food Sciences 2011; 29 616-623.

[20] Errington, N., Harding, S. E., Várum, K. M., Illum, L. Hydrodynamic characterization of chitosans varying in degree of acetylation. International Journal of Biological Macromolecules 1993; 15 113-117.

[21] Fernandez-Kim, S. O. Physicochemical and functional properties of crawfish chitosan as affected by different process protocols. Master Science Thesis. Louisiana State University and Agricultural and Mechanical College 2004.

[22] Sigma-Aldrich 2013

[23] Berth, G., Dautzenberg, H. The degree of acetylation of chitosans and its effect on the chain conformation in aqueous solution. Carbohydrate Polymers 2002; 47 39-51.

[24] Klossner, R. R., Queen, H. A., Coughlin, A. J., Krause, W. E. Correlation of chitosan's rheological properties and its ability to electrospin. Biomacromolecules 2008; 92947 2953.

[25] El-Hefian, E., Elgannoudi, E. S., Mainal, A., Yahaya, A. H. Characterization of chitosan in acetic acid: Rheological and thermal studies. Turkish Journal of Chemistry 2010; 34 47-56

[26] Abbas, Aiman Omar Mahmoud. "Chitosan for biomedical applications. " dissertation, University of Iowa 2010; http://ir. uiowa. edu/etd/77 (accessed 29 june 2013).

[27] Lertsutthiwong, P., How, N. C., Chandrkrachang, S. and Stevens, W. F. Effect of Chemical Treatment on the Characteristics of Shrimp Chitosan. Journal of Metals, Materials and Minerals 2002; 12 11-18.

[28] Abdullin, V. F., Shipovskaya, A. B., Fomina, V. I., Artemenko, S. E., Ovchinnikova, G. P., Pchelintseva, E. V. Physicochemical properties of chitosan from different raw material sources. Fibre Chemistry 2008; 40(1) 40-44.

[29] Il'ina, A. V., Varmalov, V. P. Hydrolysis of chitosan in lactic acid. Applied Biochemistry and Microbiology 2004; 40(3) 300-303.

[30] Yao, K. D., Zhao, F., Li, F., Yin, Y. J. Chitosan-based gels. In Encyclopedia of smart materials. Volume 1 and Volume 2. Schwartz, M. Ed. ; John Wiley \& Sons, Inc. : New York; 2002, 182-190.

[31] Kubota, N. Molecular weight dependence of the properties of chitosan and chitosan hydrogel for use in sustained-release drug. Bulletin of the Chemical Society of Japan 1993; 66 1807-1812.

[32] Jahren, S. L., Butler, M. F., Adams, S., Cameron, R. E. Swelling and viscoelastic characterisation of $\mathrm{pH}$-responsive chitosan hydrogels for targeted drug delivery. Macromolecular Chemistry and Physics 2010; 211 644-650. 
[33] Kikuchi, Y., Noda, A. Polyelectrolyte complexes of heparin with chitosan. Journal of Applied Polymer Science 1976; 20 2561-2563.

[34] Kratz, G., Arnander, C., Swedenborg, J., Back, M., Falk, C., Gouda, I., Larm, O. Heparin-chitosan complexes stimulate wound healing in human skin. Scandinavian Journal of Plastic and Reconstructive Surgery and Hand Surgery 1997; 31(2) 119-123.

[35] Marin, A., Andrianov, A. K. Carboxymethylcellulose-chitosan-coated microneedles with modulated hydration properties. Journal of Applied Polymer Science 2011; 121(1) 395-401.

[36] Long, D. D., Luyen, D. V. Chitosan-Carboxymethylcellulose hydrogels as supports for cell immobilization. Journal of Macromolecular Science: Pure and Applied Chemistry 1996; A33(12) 1875-1884.

[37] Shumilina, E. V., Shchipunov, Y. A. Chitosan-Carrageenan Gels. Colloid Journal 2002; 64(3) 372-378.

[38] Piyakulawat, P., Praphairaksit, N., Chantarasiri, N., Muangsin, N. Preparation and evaluation of chitosan/carrageenan beads for Controlled release of sodium diclofenac. AAPS Pharm. SciTech 2007; 8(4) E1-E11.

[39] Arof, A. K., Shuhaimi, N. E. A., Alias, N. A., Kufian, M. Z., Majid, S. R. Application of chitosan/iota-carrageenan polymer electrolytes in electrical double layer capacitor (EDLC). Journal of Solid State Electrochemistry 2010; 14(12) 2145-2152.

[40] Gotoh, T., Matsushima, K., Kikuchi, K. I. Preparation of alginate-chitosan hybrid gel beads and adsorption of divalent metal ions. Chemosphere 2004; 55 135-140.

[41] Murata, Y., Maeda, T., Miyamoto, E., Kawashima, S. Preparation of chitosan-reinforced alginate gel beads-effects of chitosan on gel matrix erosion. International Journal of Pharmaceutics 1993; 96(1-3) 139-145.

[42] Xu, Y., Zhan, C., Fan, L., Wang, L., Zheng, H. Preparation of dual crosslinked alginate-chitosan blend gel beads and in vitro controlled release in oral site-specific drug delivery system. International Journal of Pharmaceutics 2007; 336(2) 329-337.

[43] Zhang, W., Gilstrap, K., Wu, L., Bahadur, R., Moss, M. A., Wang, Q., Lu, X., He, X. Synthesis and characterization of thermally responsive Pluronic F127-chitosan nanocapsules for controlled release and Intracellular delivery of small molecules. ACS Nano 2010; 4(11) 6747-6759.

[44] Chawan-Manaspon, C., Viravaidya-Pasuwat, K., Pimpha, N. Preparation of folateconjugated Pluronic F127/chitosan core-shell nanoparticles encapsulating doxorubicin for breast cancer treatment. Journal of Nanomaterials 2012; 1-11.

[45] Kumar, R., Kasoju, N., Bora, U. Encapsulation of curcumin in alginate-chitosan-Pluronic composite nanoparticles for delivery to cancer cells. Nanomedicine \& Nanotechnology 2010; 6 153-160. 
[46] Sakiyama, T., Takata, H., Toga, T., Nakanish, K. pH-sensitive shrinking of a dextran sulfate/chitosan complex gel ad its promotion effect on the release of polymeric substances. Journal of Applied Polymer Science 2001; 81(3) 667-674.

[47] Saboktakin, M. R., Tabatabaie, R. M., Maharramov, A., Ramazanov, M. A. Synthesis and characterization of $\mathrm{pH}$-dependt glycol chitosan and dextran sulfate nanoparticles for effective brain cancer treatment. International Journal of Biological Macromolecules 2011; 49(4) 747-751.

[48] Popa, N., Novac, O., Profire, L., Lupusoru, L. E., Popa, M. I. Hydrogels based on chitosan-xanthan for controlled release of theophylline. Journal of Materials Science: Materials in Medicine 2010; 21(4) 1241-1248.

[49] Chu, C. H., Kumagai, H., Nakamura, K. Application of polyelectrolyte complex gel composed of complex gel composed of xanthan and chitosan to the immobilization of Corynebacterium glutamicum. Journal of Applied Polymer Science 1998; 60(7) 1041-1047.

[50] Izumrudov, V. A., Volkova, I. F., Gorshkova, M. Y. Chitosan-based polyelectrolyte complexes soluble in enzyme-friendly $\mathrm{pH}$ range. Macromolecular Chemistry and Physics 2010; 211 453-460.

[51] Il'ina, A. V., Varmalov, V. P. Effect of physicochemical parameters on the formation of chitosan-based gels. Applied Biochemistry and Microbiology 2004; 40(6) 599-602.

[52] Kean, T., Thanou, M. Biodegradation, biodistribution and toxicity of chitosan. Advanced Drug Delivery Reviews 2010; 62 3-11.

[53] Sogias, I. A., Williams, A. C., Khutoryanskiy, V. V. Why is chitosan mucoadhesive? Biomacromolecules 2008; 9 1837-1842.

[54] Mi, F. L., Shyu, S. S., Kuan, C. Y., Lee, S. T., Lu, K. T., Jang, S. F. Chitosan-polyelectrolyte complexation for the preparation of gel beads and controlled release of anticancer drug. I. Effect of phosphorus polyelectrolyte complex and enzymatic hydrolysis of polymer. Journal of Applied Polymer Science 1999; 74(7) 1868-1879.

[55] Furda, I. Chitin and chitosan-special class of dietary fiber. In CRC Handbook of Dietary fiber in human nutrition. 3rd Ed. ; Spiller, G. A., Ed. ; Chapter 2. 8. CRC Press: Boca Raton. 2000; 45-47.

[56] Baldrick, P. The safety of chitosan as a pharmaceutical excipient. Regulatory Toxicology and Pharmacology 2010; 56 290-299.

[57] Halim, A. S., Keong, L. C., Zainol, I., Hazri, A., Rashid, A. H. A. Biocompatibility and biodegradation of chitosan and derivatives Chapter 4. In Chitosan-based systems for biopharmaceuticals. Delivery, targeting and polymers therapeutics. Sarmento, B. ; Das Neves, J. Eds. ; Wiley: Chihester. 2012; 57-74.

[58] Dornish, M., Kaplan, D. S., Arapalli, S. R. Regulatory status of chitosan and derivatives. Chapter 24. In Chitosan-based systems for biopharmaceuticals. Delivery, tar- 
geting and polymers therapeutics. Sarmento, B. ; Das Neves, J. Eds. ; Wiley: Chihester. 2012; 463- 482.

[59] Leithner, K., Bernkop-Schnürch, A. Chitosan and derivatives for biopharmaceutical use: Mucoadhesive properties. Chapter 10. In Chitosan-based systems for biopharmaceuticals. Delivery, targeting and polymers therapeutics. Sarmento, B. ; Das Neves, J. Eds. ; Wiley: Chihester. 2012; 159-180.

[60] Gooday, G. W. Physiology of microbial degradation of chitin and chitosan. Biodegradation 1990; 1, 177-190.

[61] Diab, M. A., El-Sombati, A. Z., Bader, D. M., Zoromba, M. S. Thermal stability and degradation of chitosan modified by acetophenone. Journal of Polymers and the Environment 2012; 20 29-36.

[62] Georgieva, V., Zvezdova, D., Vlaev, L. Non-isothermal kinetics of thermal degradation of chitosan. Chemistry Central Journal 2012; 6(81) 1-10.

[63] Park, J. K., Chung, M. J., Choi, H. H., Park Y. I. Effects of the molecular weight and the degree of deacetylation of chitosan oligosaccharides on antitumor activity. International Journal of Molecular Sciences 2011; 12(1) 266-277.

[64] Ghazizadeh, Y., Mirzadeh, H., Amanpour, S., Ahmadi, H., Rabbani, S. Investigation of Effectiveness of Chitosan Hydrogel to Stop Bleeding and Air Leakage from Lung Fistula: An In Vivo Study. Iranian Polymer Journal 2006; 15(10) 821-828

[65] Sugano, M., Watanabe, S., Kishi, A., Izume, M., Ohtakara, A. Hypocholesterolemic action of chitosans with different viscosity in rats. Lipids 1988; 23 187-191.

[66] Deuchi, K., Kanauchi, O., Shizukuishi, M., Kobayashi, E. Continuous and massive intake of chitosan affects mineral and fat-soluble vitamin status in rats fed on a high-fat diet. Bioscience, Biotechnology, and Biochemistry 1995; 59 (7) 1211-1216.

[67] Sivakumar, R., Rajesh, R., Buddhan, S., Jeyakumar, R., Rajaprabhu, D., Ganesan, B., Anandan, R. Antilipidemic effect of chitosan against experimentally induced myocardial infarction in rats. Journal of Cell and Animal Biology, 1 (4), pp. 071-077

[68] Sumiyoshi, M., Kimura, Y. Low molecular weight chitosan inhibits obesity induced by feeding a high-fat diet long-term in mice. Journal of Pharmacy and Pharmacology 2006; 58(2) 201-7.

[69] Liu, N., Chen, X. G., Park, H. J., Liu, C. G., Liu, C. S., Meng, X. H., Yu, L. J. Effect of MW and concentration of chitosan on antibacterial activity of Escherichia coli. Carbohydrate Polymers 2006; 64(1) 60-65.

[70] Zheng, L. Y., Zhu, J. F. Study on antimicrobial activity of chitosan with different molecular weights. Carbohydrate. Polymers 2003; 54(4) 527-530. 
[71] Zivanovic, S., Basurto, C. C., Chi, S., Davidson, P. M., Weiss, J. Molecular weight of chitosan influences antimicrobial activity inoil-in water emulsions. Journal of Food Protection 2004; 67(5), 952-959.

[72] Sano, H., Shibasaki, K., Matsukubo, T., Takaesu, Y. Effect of molecular mass and degree of deacetylation of chitosan on adsorption of Streptococcus sobrinus 6715 to saliva treated hydroxyapatite. Bulletin of Tokyo Dental College 2002; 43(2) 75-82.

[73] Carreño-Gómez, B., Duncan, R. Evaluation of the biological properties of soluble chitosan and chitosan microspheres, International Journal of Pharmaceutics 1997; 148 231-240.

[74] Opanasopit, P., Aumklad, P., Kowapradit, J., Ngawhiranpat, T., Apirakaramwong, A., Rojanarata, T., Puttipipatkhachorn, S. Effect of salt forms and molecular weight of chitosans on in vitro permeability enhancement in intestinal epithelial cells (caco-2). Pharmaceutical Development and Technology 2007; 12 447-455

[75] Cleenewerck, M. B., Martin, P. Laurent, D. Allergic contact dermatitis due to a moisturizing body cream with chitin. Contact Dermatitis 1994; 31(3): 196-197.

[76] Kato, Y, Yagami, A., Matsunaga K. A case of anaphylaxis caused by the health food chitosan. Arerugi 2005; 54(12): 1427-1429.

[77] Pereira, F., Pereira, C. Lacerda, MH. Contact dermatitis due to a cream containing chitin and a Carbitol. Contact Dermatitis 1998; 38(5): 290-291.

[78] Arai K, Kinumaki T, Fujita T. Toxity of chitosan. Bulletin Tohoku Regional Fisheries Research Laboratory 1968; 56, 89-94.

[79] Sonaje K, Lin YH, Juang JH, Wey SP, Chen CT, Sung HW. In vivo evaluation of safety and efficacy of self-assembled nanoparticles for oral insulin delivery. Biomaterials 2009;30, 2329-39.

[80] Illum L, Farraj NF, Davis SS. Chitosan as a novel nasal delivery system for peptide drugs. Pharmaceutical Research 1994;11:1186-9.

[81] Waibel K. H., Haney, B., Moore, M., Whisman, B., Gomez, R. Safety of chitosan bandages in shellfish allergic patients. Military Medicine 2001; 176 (10):1153-1156.

[82] Kulish, E. I., Volodina, V. P., Fatkullina, R. R., Kolesov, S. V., Zaiko, G. E. Macromolecular effects upon enzymatic degradation of chitosan in solution. Polymer Science Series B 2008; 50(7-8) 172-174.

[83] Kulish, E. I., Volodina, V. P., Kolesov, S. V., Zaikov, G. E. Enzymatic degradation of chitosan films by collagenase. Polymer Science Series B 2006; 48(9-10) 244-246.

[84] Nakashima, T., Nakano, Y., Bin, Y. Biodegradation characteristics of chitin and chitosan films. Journal of home economics of Japan 2005; 56(12) 889-897. 
[85] Choi, W. S., Ahn, K. J., Lee, D. W., Byun, M. W., Park, H. J. Preparation of chitosan oligomers by irradiation. Polymer Degradation and Stability 2002; 78 533-538.

[86] Balau, L., Lisa, G., Popa, M., Tura, V., Melnig, V. Physico-chemical properties of chitosan films. Central European Journal of Chemistry 2004; 2(4) 638-647.

[87] Ormrod, D. J., Holmes, C. C., Miller, T. E. Dietary chitosan inhibits hypercholesterolaemia and atherogenesis in the apolipoprotein E-deficient mouse model of atherosclerosis. Atherosclerosis 1998; 138(2) 329-334.

[88] Jing, S. B., Li, L., Ji, D., Takiguchi, Y., Yamaguchi, T., Effect of chitosan on renal function in patients with chronic renal failure. Journal of Pharmacy and Pharmacology 1997; 49(7) 721.

[89] Sciutto, A. M., Colombo, P., Lipid - lowering effect of chitosan dietary integrator and hypocaloric diet in obese subjects. Acta Toxicology and Therapeutics 1995; 16(4) 215-230.

[90] Tapola, N. S., Lyyra, M. L., Kolehmainen, R. M., Sarkkinen, E. S., Schauss, A. G. Safety aspects and cholesterol-lowering efficacy of chitosan tablets. Journal of the American College of Nutrition 2008; 27(1) 22-30.

[91] Kim, J. K., Han, K. H., Lee, J. T., Paik, Y. H., Ahn, S. H., Lee, J. D., Lee, K. S., Chon, C. Y., Moon, Y. M. Long-term clinical outcome of phase IIb clinical trial of percutaneous injection with holmium-166/chitosan complex (Milican) for the treatment of small hepatocellular carcinoma. Clinical Cancer Research 2006; 12(2) 543-8.

[92] Kato, H., Taguchi, T., Okuda, H., Kondo, M., and Takara, M. Antihypertensive effect of chitosan in rats and humans. Journal of Traditional Medicine 1994; 1 198-205

[93] Bokura, H., Kobayashi, S. Chitosan decreases total cholesterol in women: a randomized, double-blind, placebo-controlled trial. European Journal of Clinical Nutrition 2003; 57(5) 721-5.

[94] Kanauchi, O., Deuchi, K., Imasato, Y., Shizukuishi, M., Kobayashi, E. Mechanism for the inhibition of fat digestion by chitosan and for the synergistic effect of ascorbate. Bioscience, Biotechnology, and Biochemistry 1995; 59 786-790.

[95] Jennings, C. D., Boleyn, K., Bridges, S. R., Wood, P. J., Anderson, J. W. A comparison of the lipid-lowering and intestinal morphological effects of cholestyramine, chitosan, and oat gum in rats. Proceedings of the Society for Experimental Biology and Medicine 1988; 189 13-20.

[96] Bartone, F. F., Adickes, E. D. Chitosan: Effects on wound healing in urogenital tissue: Preliminary report. Journal of Urology 1988; 140 1134-1137.

[97] Rao, S. B., Sharma, C. P. Use of chitosan as a biomaterial: studies on its safety and hemostatic potential. Journal of Biomedical Materials Research 1997; 34(1) 21-28. 
[98] Laffleur, F., Hintzen, F., Rahmat, D., Shahnaz, G., Millotti, G., Bernkop-Schnürch, A. Enzymatic degradation of thiolated chitosan. Drug Development and Industrial Pharmacy 2013; 39(10): 1531-1539.

[99] Ren D., Yi, H., Ma, X. The enzymatic degradation and swelling properties of chitosan matrices with different degrees of N-acetylation. Carbohydrate Research 2005; 340 (15) 2403-2410.

[100] Zhang L., Dou, S., Li, Y., Yuan, Y., Ji, Y., Wang, Y., Yang, Y. Degradation and compatibility behaviors of poly(glycolic acid) grafted chitosan. Materials Science and Engineering C 33 2013; 5, 2626-2631.

[101] Kurita K., Kaji, Y., Mori, T., Nishiyama, Y. Enzymatic degradation of $\beta$-chitin: susceptibility and the influence of deacetylation. Carbohydrate Polymers 2000; 42 (1): 19-21.

[102] Wang, PL., Johnston, TP. Enhanced stability of two model proteins in an agitated solution environment using poloxamer 407. Journal of Parenteral Science and Technology 1993; 47(4) 183-9.

[103] Illum L. Nasal drug delivery - possibilities, problems and solutions. Journal of Controlled Release 2003, 87, 187-198.

[104] Teijeiro-Osorio D., Remunán-López C., José Alonso M. New generation of hybrid poly oligosaccharide nanoparticles as carriers for the nasal delivery of macromolecules. Biomacromolecules 2008, 10, 243-249.

[105] Zhang, N. ; Ping, QN. ; Huang, GH. ; Xu, WF. Investigation of lectin modified insulin liposomes as carriers for oral administration. International Journal of Pharmceutics. 2005, 294(1-2), 247-259.

[106] Fernández-Urrusuno R., Calvo P., Remunán-López C., Vila-Jato J. L., José Alonso M. Enhancement of nasal absorption of insulin using chitosan nanoparticles. Pharmaceutical Research 1999, 16, 1576-1581.

[107] Sui, Z., Chen, Q., Fang, F., Zheng, M., Chen, Z. Cross-protection against influenza virus infection by intranasal administration of M1-based vaccine with chitosan as an adjuvant. Vaccine 2010; 28(48) 7690-7698.

[108] Günbeyaz, M., Faraji, A., Ozkul, A., Puralı, N., Senel, S. Chitosan based delivery systems for mucosal immunization against bovine herpesvirus 1 (BHV-1). European Journal of Pharmaceutical Sciences 2010; 41(3-4) 531-545.

[109] Addo, R. T., Siddig, A., Siwale, R., Patel, N. J., Akande, J., Uddin, A. N., D’Souza, M. J. Formulation, characterization and testing of tetracaine hydrochloride-loaded albumin-chitosan microparticles for ocular drug delivery. Journal of Microencapsulation. 2010; 27, 95-104. 
[110] Alhalaweh, A., Andersson, S., Velaga, S. P. Preparation of zolmitriptan-chitosan microparticles by spray drying for nasal delivery. European Journal of Pharmaceutical Sciences. 2009; 38, 206-214.

[111] Gavini, E., Hegge, A. B., Rassu, G., Sanna, V., Testa, C., Pirisino, G., Karlsen, J., Giunchedi, P. Nasal administration of carbamazepine using chitosan microspheres: in vitro/in vivo studies. International Journal of Pharmaceutics. 2006; 307, 9-15.

[112] Kusonwiriyawong, C., Pichayakorn, W., Lipipun, V., Ritthidej, G. C. Retained integrity of protein encapsulated in spray-dried chitosan microparticles. Journal of Microencapsulation. 2009; 26, 111-121.

[113] Gordon, S., Saupe, A., McBurney, W., Rades, T., Hook, S. Comparison of chitosan nanoparticles and chitosan hydrogels for vaccine delivery. Journal of Pharmacy and Pharmacology. 2008; 60, 1591-1600.

[114] Jiang, H. L., Kang, M. L., Quan, J. S., Kang, S. G., Akaike, T., Yoo, H. S., Cho, C. S. The potential of mannosylated chitosan microspheres to target macrophage mannose receptors in an adjuvant-delivery system for intranasal immunization. Biomaterials. 2008; 29, 1931-1939.

[115] Kang, M. L. ; Jiang, H. L. ; Kang, S. G. ; Guo, D. D. ; Lee, D. Y.. ; Cho, C. S. ; Yoo, H. S. Pluronic F127 enhances the effect as an adjuvant of chitosan microspheres in the intranasal delivery of Bordetella bronchiseptica antigens containing dermonecrotoxin. Vaccine. 2007, 25(23), 4602-10.

[116] Holmgren, J., Czerkinsky, C. Mucosal immunity and vaccines. Nature Medicine. 2005; 11 45-53.

[117] Senel, S., Kremer MJ., Kas, HS., Wertz, PW., Hincal, AA., Squier, CA. Advances in Chitin Science. In Peter, MG., Muzzarelli, R. A. A., Domard A. (Eds. ). University of Potsdam 2000, 4, 254- 258.

[118] Kremer, MJ, Senel, S., Kas, SH., Wertz, PW., Hincal, AA., Squier, C. A. Oral mucosal drug delivery: chitosan as vehicle and permeabilizer. Journal of Dental Research $1999,77,718$.

[119] Shin SC., Kim, JY., Oh, IJ. Mucoadhesive and physicochemical characterization of carbopol-poloxamer gels containing triamcinolone acetonide. Drug Development and Industrial Pharmacy 2000; 26(3) 307-312.

[120] Omwanchaa, W. S., Mallipeddi, R., Valle, B. L., Neau, S. H. Chitosan as a pore former in coated beads for colon specific drug delivery of 5-ASA. International Journal of Pharmaceutics 2013; 441 343-351.

[121] Cho, KY., Chung, TW., Kim, BC., Kim, MK., Lee, JH.., Wee, WR., Cho, CS. Release of ciprofloxacin from poloxamer-graft-hyaluronic acid hydrogels in vitro. International Journal of Pharmaceutics 2003; 260(1) 83-91. 
[122] Ruel-Gariepy, E., Leclair, G., Hildgen, P., Gupta, A., Leroux, JC. Thermosensitive chitosan-based hydrogel containing liposomes for the delivery of hydrophilic molecules. Journal of Controlled Release 2002; 82(2-3) 373-383.

[123] Qiao, MX., Chen, DW., Ma, XC., Liu, YJ. Injectable biodegradable temperature-responsive PLGA-PEG-PLGA copolymers: synthesis and effect of copolymer composition on the drug release from the copolymer based hydrogels. International Journal of Pharmaceutics 2005; 294(1-2) 103-112.

[124] Bromberg, L. Interactions among proteins and hydrophobically modified polyelectrolytes. Journal of Pharmacy and Pharmacology 2001; 53(4) 541-547.

[125] Bromberg, L. Enhanced nasal retention of hydrophobically modified polyelectrolytes. Journal of Pharmacy and Pharmacology 2001; 53(1) 109-114.

[126] Bromberg, L. Synthesis and self-assembly of poly(ethylene oxide)- b-poly(propylene oxide)-b-poly(ethylene oxide)-g-poly(acrylic acid). Industrial \& Engineering Chemistry Research 2001; 40(11) 2437-2444.

[127] De Campos, AM., Sánchez, A., Alonso, MJ. Chitosan nanoparticles: a new vehicle for the improvement of the delivery of drugs to the ocular surface. Application to cyclosporin A. International Journal of Pharmaceutics 2001; 224(1-2) 159-168.

[128] Genta I., Conti B., Perugini P., Pavanetto F., Spadaro A., Puglisi G. Bioadhesive microspheres for ophthalmic administration of acyclovir, J. Pharm. Pharmacol. 49 (1997) 737-742.

[129] Wassmer, S., Rafat, M., Fong, W. G., Baker, A. N., Tsilfidis C. Chitosan microparticles for delivery of proteins to the retina. Acta Biomaterialia 2013; 9 7855-7864.

[130] Domínguez-Delgado, CL., Rodríguez-Cruz IM., López-Cervantes, M. The Skin a Valuable Route for Administration Of Drugs. In Current Technologies To Increase The Transdermal Delivery Of Drugs, Escobar-Chávez, JJ. ; Merino, V., Eds. Bentham Science Publishers Ltd 2010; 01-22.

[131] Escobar-Chávez, JJ., Rodríguez-Cruz IM., Domínguez-Delgado CL. Chemical and physical enhancers for transdermal drug delivery. In: Pharmacology, Galleli, L., Ed. ; Tech Croatia, 2012; 397-434.

[132] Escobar-Chávez, JJ., Díaz-Torres, R., Rodríguez-Cruz, IM., Domínguez-Delgado, CL., Sampere Morales, R., Ángeles-Anguiano, E., Melgoza-Contreras, LM. Nanocarriers for transdermal drug delivery. Research and Reports in Transdermal Drug Delivery 2012; 1, 3-17.

[133] Escobar-Chávez, JJ., Rodríguez-Cruz, IM., Domínguez-Delgado, CL., Díaz- Torres, R., Revilla-Vázquez, AL., Casas Aléncaster, N. Nanocarrier systems for transdermal drug delivery. In Recent Advances in Drug Carrier Systems, Demir Sezer, A. Ph. D., Ed. ; InTech Croatia, 2012; 201-240. 
[134] Domínguez-Delgado, CL., Rodríguez-Cruz, IM., Escobar-Chávez, JJ., Calderón-Lojero, IO., Quintanar-Guerrero, D., Ganem-Quintanar, A. Triclosan nanoparticles as a novel option for acne treatment. European Journal of Pharmaceutics and Biopharmaceutics 2011; 79(1) 102-107.

[135] Thein-Han, WW., Stevens, WF. Transdermal delivery controlled by a chitosan membrane. Drug Development and Industrial Pharmacy 2004; 30(4) 397-404.

[136] Khalil, S. K. H., El-Feky, G. S., El-Banna, S. T., Khalil, W. A. Preparation and evaluation of warfarin- $\beta$-cyclodextrin loaded chitosan nanoparticles for transdermal delivery. Carbohydrate Polymers 2012; 90 1244-1253

[137] Dash, M., Chiellini, F., Ottenbrite, RM., Chiellini. E. Chitosan-A versatile semi-synthetic polymer in biomedical applications. Progress in Polymer Science 2011; 36(8) 981-1014.

[138] Ladet, SG., Tahiri, K., Montembault AS., Domard, AJ., Corvol, MT. Multimembrane chitosan hydrogels as chondrocytic cell bioreactors. Biomaterials 2011; 32(23) 535464 .

[139] Seol, YJ., Lee, JY., Park, YJ., Lee, YM., Young, K., Rhyu, IC., Lee, SJ., Han, SB., Chung, $\mathrm{CP}$. Chitosan sponges as tissue engineering scaffolds for bone formation. Biotechnology Letters 2004; 26(13) 1037-41.

[140] Lee, KH., Shin, SJ., Kim, CB., Kim, JK., Cho, YW., Chung, BG., Lee, SH. Microfluidic synthesis of pure chitosan microfibers for bio-artificial liver chip. Lab on a Chip 2010; 10(10) 1328-34.

[141] Lueßen H. L., de Leeuw B. J., Langemeÿer M. W. E., de Boer A. G., Verhoef J. C., Junginger H. E. Mucoadhesive polymers in peroral peptide drug delivery. VI. Carbomer and chitosan improve the intestinal absorption of the peptide drug buserelin in vivo. Pharmaceutical Research 1996, 13, 1668-1672.

[142] Jintapattanakit A., Junyaprasert V. B., Kissel T. The role of mucoadhesion of trimethyl chitosan and PEGylated trimethyl chitosan nanocomplexes in insulin uptake, Journal of Pharmaceutical Sciences 2009, 98, 4818-4830.

[143] Werle M., Bernkop-Schnürch A. Thiolated chitosans: useful excipients for oral drug delivery, Journal of Pharmacy and Pharmacology 2008, 60, 273-281.

[144] Crini G, Badot PM. Application of chitosan, a natural aminopolysaccharide, for dye removal from aqueous solutions by adsorption processes using batch studies: a review of recent literature. Progress in Polymer Science 2008, 33:399-447.

[145] George M, Abraham TE. Polyionic hydrocolloids for the intestinal delivery of protein drugs: alginate and chitosan. Journal of Controlled Release 2006;114:1-14. 
[146] Chang, CH., Lin, YH., Yeh, CL., Chen, YC., Chou SF., Hsu, YM., Chen, YS., Wang, CC. Nanoparticles incorporated in $\mathrm{pH}$-sensitive hydrogels as amoxicillin delivery for eradication of Helicobacter pylori. Biomacromolecules 2010; 11(1) 133-42.

[147] Gisbert, JP., Torrado, G., Torrado, S., Olivares, D., Pajares, JM. Clinical trial evaluating amoxicillin and clarithromycin hydrogel (chitosan-polyacrylic acid polyionic complexes) for H. pylori eradiction. Journal of Clinical Gastroenterology 2006; 40(7) 618-22.

[148] Dhaliwal S., Jain S, Singh H, Tiwary A. Mucoadhesive microspheres for gastroretentive delivery of acyclovir: in vitro and in vivo evaluation. American Association of pharmaceutical scientists Journal 2008, 10, 322-330.

[149] Morishita, M. ; Goto, T. ; Nakamura, K. ; Lowman, AM. ; Takayama, K. ; Peppas, NA. Novel oral insulin delivery systems based on complexation polymer hydrogels: single and multiple administration studies in type 1 and 2 diabetic rats. Journal of Controlled Release. 2006, 110(3), 587-594.

[150] Yamagata, T. ; Morishita, M. ; Kavimandan, NJ. ; Nakamura, K. ; Fukuoka, Y. ; Takayama, K. ; Peppas, NA. Characterization of insulin protection properties of complexation hydrogels in gastric and intestinal enzyme fluids. Journal of Controlled Release. 2006, 112(3), 343-349.

[151] Mesiha, MS. ; Sidhom, MB. ; Fasipe, B. Oral and subcutaneous absorption of insulin poly(isobutylcyanoacrylate) nanoparticles. International Journal of Pharmceutics. 2005, 288(2), 289-293.

[152] Degim, IT. ; Gumusel, B. ; Degim, Z. ; Ozcelikay, T. ; Tay, A. ; Guner, S. Oral administration of liposomal insulin. Journal of Nanoscience and Nanotechnology 2006, 6(9-10), 2945-2949.

[153] Zhang X., Zhang H., Wu Z., Wang Z., Niu H., Li C. Nasal absorption enhancement of insulin using PEG-grafted chitosan nanoparticles. European Journal of Pharmaceutics and Biopharmaceutics 2008, 68, 526-534.

[154] Alonso-Sande, M. ; Cuna, M. ; Remunan-Lopez, C. ; Teijeiro-Osorio, D. ; Alonso-Lebrero, JL. ; Alonso, MJ. Formation of new glucomannan-chitosan nanoparticles and study of their ability to associate and deliver proteins. Macromolecules 2006, 39(12), 4152-4158.

[155] Besheer, A. ; Wood, KM. ; Peppas, NA. ; Mader, K. Loading and mobility of spin-labeled insulin in physiologically responsive complexation hydrogels intended for oral administration. Journal of. Controlled Release. 2006, 111(1-2), 73-80.

[156] Wei W., Guang-Hui Maa, Lian-Yan Wanga, Jie Wua, Zhi-Guo Su. Hollow quaternized chitosan microspheres increase the therapeutic effect of orally administered insulin. Acta Biomaterialia 2010, 6, 205-209. 
[157] Anil K. Anal, Willem F. Stevens, Remuñañ-López C. Ionotropic cross-linked chitosan microspheres for controlled release of ampicillin. International Journal of Pharmaceutics 2006, 312, 166-173

[158] Remuñañ-López, C., Portero, A., Lemos, M., Vila-Jato, J. L., Nuñez, M. J., Riveiro, P., López, J. M., Piso, M., Alonso, M. J. Chitosan microspheres for specific delivery of Amoxycillin to the gastric cavity. S. T. P. Pharma Sciences 2000, 10 (1), 69-76.

[159] Ishak R, Awad G. Zaki N, El-Hamid A, El-Shamy, Mortada N. D. A comparative study of chitosan shielding effect on nano-carriers hydrophilicity and biodistribution Carbohydrate Polymers 94 (2013) 669-676.

[160] Singh, K., Tiwary, A. K., Rana, V. Spray dried chitosan-EDTA superior microparticles as solid substrate for the oral delivery of amphotericin B. International Journal of Biological Macromolecules 2013; 58 310-319.

[161] Suksamran, T., Ngawhirunpat, T., Rojanarata, T., Sajomsang, W., Pitaksuteepong, T., Opanasopit, P. Methylated N-(4-N, N-dimethylaminocinnamyl) chitosan-coated electrospray OVA-loaded microparticles for oral vaccination. International Journal of Pharmaceutics 2013; 448 19-27.

[162] Zhang, J., Tang, C., Yin, C. Galactosylated trimethyl chitosan-cysteine nanoparticles loaded with Map4k4siRNA for targeting activated macrophages. Biomaterials 2013; 34 3667-3677.

[163] Aiedeh K, Taha M. O. Synthesis of iron-crosslinked chitosan succinate and ironcrosslinked hydroxamated chitosan succinate and their in vitro evaluation as potential matrix materials for oral theophylline sustainedrelease beads. European. Journal of Pharmaceutical Sciences 2001;13 159-168.

[164] Miyazaki, S., Nakayama, A., Oda, M., Takada, M., Attwood, D. Drug release from oral mucosal tablets of chitosan and sodium alginate. International Journal of Pharmaceutics $1995 ; 118(2)$ 257-263.

[165] Remunan-Lopez, C., Portero, A., Vila-Jato, JL., Alonso, MJ. The design and evaluation of chitosan: ethylcellulose mucoadhesive bilayered devices for buccal drug delivery. Journal of Controlled Release 1998; 55(2-3) 143- 152.

[166] Kotze, AF., Luessen, HL., De Leeuw, BJ., De Boer, AG., Verhoef, JC., Junginger, HE. Comparison of the effect of different chitosan-salts and N-trimethyl-chitosan chloride on the permeability of intestinal epithelial cells (Caco-2). Journal of Controlled Release 1998; 51(1) 35-46.

[167] Ritthidej, G. C., Phaechamud T., Koizumi T. Moist heat treatment on physicochemical change of chitosan salt films. International Journal of Pharmaceutics 2002, 23(1-2), 211-22. 
[168] Cafaggi, S. ; Leardi, R. ; Parodi, B. ; Caviglioli, G. ; Russo, E., Bignardi, G. Preparation and evaluation of a chitosan salt-poloxamer 407 based matrix for buccal drug delivery. Journal of Controlled Release. 2005, 102(1), 159-169

[169] Sandri G, Rossi S, Bonferoni M. C, Ferrari F, Zambito Y, Di Colo G, Caramella C. Buccal penetration enhancement properties of $\mathrm{N}$-trimethyl chitosan: influence of quaternization degree on absorption of a high molecular weight molecule. International Journal of Pharmaceutics 2005, 297, 146-155.

[170] Langoth N, Kahlbacher H, Schöffmann G, Schmerold I, Schuh M, Franz S, Kurka P, Bernkop-Schnürch A. Thiolated chitosans: design and in vivo evaluation of a mucoadhesive buccal peptide drug delivery system. Pharmaceutical Research 2006, 23, 573-579.

[171] Bernkop-Schnürch A, Dünnhaupt S. Chitosan-based drug delivery systems. European Journal of Pharmaceutics and Biopharmaceutics 2012; 81, 463-469.

[172] Artursson P, Lindmark T, Davis S, Illum L. Effect of chitosan on the permeability of monolayers of intestinal epithelial cells (Caco-2). Pharmaceutical Research 1994, 11, 1358-1361.

[173] Schipper N. G., Olsson S., Hoogstraate J. A., De Boer A. G., Varum K. M., Artursson P. Chitosans as absorption enhancers for poorly absorbable drugs 2: mechanism of absorption enhancement. Pharmaceutical Research 1997, 14, 923-929.

[174] Macleod G. S., Fell J. T., Collett J. H., Sharma H. L., Smith A. -M. Selective drug delivery to the colon using pectin:chitosan:hydroxypropyl methylcellulose film coated tablets. International Journal of Pharmaceutics 1999, 187, 251-257.

[175] Bernkop-Schnürch A., Reich-Rohrwig E., Marschütz M., Schuhbauer H., Kratzel M. Development of a sustained release dosage form for a-lipoic acid. II. Evaluation in human volunteers. Drug Development and Industry Pharmaacy 2004, 30, 35-42.

[176] Jain SK. ; Jain A. ; Gupta Y. ; Ahirwar M. Design and development of hydrogel beads for targeted drug delivery to the colon. American Association of pharmaceutical scientists Technology 2007, 8(3), E56.

[177] Huang Y, Onyeri S, Siewe M, Moshfeghian A, Madihally SV. In vitro characterization of chitosan-gelatin scaffolds for tissue engineering. Biomaterials 2005; 26:7616-27.

[178] Sarasam A, Madihally SV. Characterization of chitosan-polycaprolactone blends for tissue engineering applications. Biomaterials 2005; 26:5500-8.

[179] Hsieh CY, Tsai SP, Wang DM, Chang YN, Hsieh HJ. Preparation of gamma-PGA/ chitosan composite tissue engineering matrices. Biomaterials 2005; 26:5617-23.

[180] Chung TW, Lu YF, Wang SS, Lin YS, Chu SH. Growth of human endothelial cells on photochemically grafted Gly-Arg-Gly-Asp (GRGD) chitosans. Biomaterials 2002; 23:4803-9. 
[181] Chung TW, Yang J, Akaike T, Cho KY, Nah JW, Kim SI, et al. Preparation of alginate/ galactosylated chitosan scaffold for hepatocyte attachment. Biomaterials 2002;23:2827-34.

[182] Grenha A, Seijo B, Remunan-Lopez C. Microencapsulated chitosan nanoparticles for lung protein delivery. European. Journal of Pharmaceutical Sciences 2005, 25, 427437.

[183] Grenha A, Grainger C. I., Dailey L. A, Seijo B, Martin G. P., Remunan-Lopez C, Forbes $\mathrm{B}$. Chitosan nanoparticles are compatible with respiratory epithelial cells in vitro. European. Journal of Pharmaceutical Sciences 2007, 31, 73-84.

[184] Grenha A., Remunan-Lopez C., Carvalho E. L. S., Seijo B. Microspheres containing lipid/chitosan nanoparticles complexes for pulmonary delivery of therapeutic proteins. European Journal of Pharmaceutics and Biopharmaceutics. 2008, 69, 83-93.

[185] Lim S. T., Forbes B., Martin G. P., M. B. Brown, In vivo and in vitro characterization of novel microparticulates based on hyaluronan and chitosan hydroglutamate. American Association of pharmaceutical scientists Technology 2001, 2, 20.

[186] Yang M., Velaga S., Yamamoto H., Takeuchi H., Kawashima Y., Hovgaard L., van de Weert M., Frokjaer S. Characterisation of salmon calcitonin in spray-dried powder for inhalation. Effect of chitosan, International Journal of Pharmaceutics. 2007, 331, 176-181.

[187] Yamamoto H., Kuno Y., Sugimoto S., Takeuchi H., Kawashima Y. Surface modified PLGA nanosphere with chitosan improved pulmonary delivery of calcitonin by mucoadhesion and opening of the intercellular tight junctions. Journal of Controlled Release 2005, 102, 373-381.

[188] Yamada K., Odomi M., Okada N., Fujita T., Yamamoto A. Chitosan oligomers as potential and safe absorption enhancers for improving the pulmonary absorption of interferon-alpha in rats. Journal of Pharmaceutical Sciences 2005, 94, 2432-2440.

[189] Amidi M., Pellikaan H. C., de Boer A. H., Crommelin D. J., Hennink W. E., Jiskoot W. Preparation and physicochemical characterization of supercritically dried insulinloaded microparticles for pulmonary delivery. European Journal of Pharmaceutics and Biopharmaceutics 2008, 68, 191-200.

[190] Trapani, A., Di Gioia, S., Ditaranto, N., Cioffi, N., Goycoolea, F. M., Carbone, A., Garcia-Fuentes, M., Conese, M., Alonso, M. J. Systemic heparin delivery by the pulmonary route using chitosan and glycol chitosan nanoparticles. International Journal of Pharmaceutics 2013; 447 115-123.

[191] Park, J. H., Jin, H. E., Kim, D. D., Chung, S. J., Shim, W. S, Shim, C. K. Chitosan microspheres as an alveolar macrophage delivery system of ofloxacino via pulmonary inhalation. International Journal of Pharmaceutics 2013; 441 562-569. 
[192] Bhumkar D. R., Joshi H. M., Sastry M., Pokharkar V. B. Chitosan reduced gold nanoparticles as novel carriers for transmucosal delivery of insulin. Pharmaceutical Research 2007, 24, 1415-1426.

[193] Soane R. J., Frier M., Perkins A. C., Jones N. S., Davis S. S., Illum L. Evaluation of the clearance characteristics of bioadhesive systems in humans. International Journal of Pharmaceutics. 1999, 178, 55-65.

[194] Na L., Mao S., Wang J., Sun W. Comparison of different absorption enhancers on the intranasal absorption of isosorbide dinitrate in rats. International Journal of Pharmaceutics. 2010, 397, 59-66.

[195] Fisher A., Watling M., Smith A., Knight A. Pharmacokinetic comparisons of three nasal fentanyl formulations; pectin, chitosan and chitosan-poloxamer 188. International Journal of Clinical Pharmacology and Therapeutics 2010, 48, 138-145.

[196] Kang, ML. ; Kang, SG. ; Jiang, HL. ; Guo, DD. ; Lee, DY. ; Rayamahji, N. ; Seo, YS. ; Cho, CS. ; Yoo, HS. Chitosan microspheres containing Bordetella bronchiseptica antigens as novel vaccine against atrophic rhinitis in pigs. J Microbiol Biotechnol. 2008, $18(6), 1179-85$.

[197] Kang, ML., Kang, SG., Jiang, HL., Shin, SW., Lee, DY., Ahn, JM., Rayamahji, N., Park, IK., Shin, SJ., Cho, CS., Yoo, HS. In vivo induction of mucosal immune responses by intranasal administration of chitosan microspheres containing Bordetella bronchiseptica DNT. European Journal of Pharmaceutics and Biopharmaceutics 2006; 63(2) 21520.

[198] Neutra, MR., Kozlowski, PA. Mucosal vaccines: the promise and the challenge. Nature Reviews Immunology 2006; 6(2) 148-58.

[199] Escobar-Chávez, JJ., Domínguez-Delgado, CL., Rodríguez-Cruz, IM. Targeting nicotine addiction: the possibility of a therapeutic vaccine. Drug Design: Development and Therapy; 2011, 5 211-224.

[200] Westerink, MA., Smithson, SL., Srivastava, N., Blonder, J., Coeshott, C., Rosenthal, GJ. ProJuvant (Pluronic F127/chitosan) enhances the immune response to intranasally administered tetanus toxoid. Vaccine 2001; 20(5-6) 711-23.

[201] Rokhade, AP., Shelke, NB., Patil, SA., Aminabhavi, TM. Novel hydrogel microspheres of chitosan and pluronic F-127 for controlled release of 5-fluorouracil. Journal of Microencapsulation 2007; 24(3) 274-88.

[202] Kumar, M., Pandey, R. S., Patra, K. C, Jain, S. K., Soni, M. L, Dangi, J. S, Madan, J. Evaluation of neuropeptide loaded trimethyl chitosan nanoparticles for nose to brain delivery. International Journal of Biological Macromolecules 2013; http://dx. doi. org/10. 1016/j. ijbiomac. 2013. 06. 041

[203] Gupta H, Velpandian T, Jain S. Ion- and pH-activated novel in-situ gel system for sustained ocular drug delivery, J. Drug Targeting 18 (2010) 499-505. 
[204] Calvo P., Vila-Jato J. L., Alonso M. a. J. Evaluation of cationic polymer-coated nanocapsules as ocular drug carriers. International Journal of Pharmaceutics. 153 (1997) 41-50.

[205] Felt, O., Furrer, P., Mayer JM., Plazonnet, B., Buri, P., Gurny, R. Topical use of chitosan in ophthalmology: tolerance assessment and evaluation of pre-corneal retention. International Journal of Pharmaceutics 1999; 180(2) 185-193.

[206] Mi, FL., Sung, HW., Shyu, SS. Drug release from chitosan-alginate complex beads reinforced by a naturally occurring crosslinking agent. Carbohydrate Polymers 2002; 48(1) 61-72.

[207] Coppi, G., Iannuccelli, V., Leo, E., Bernabei, MT., Cameroni, R. Protein immobilization in crosslinked alginate microparticles. Journal of Microencapsulation 2002; 19(1) 37-44.

[208] Gonzalez-Rodriguez, ML., Holgado, MA., Sanchez-Lafuente, C., Rabasco, AM., Fini, A. Alginate/chitosan particulate systems for sodium diclofenac release. International Journal of Pharmaceutics 2002; 232(1-2) 225-234.

[209] Takka, S., Acarturk, F. Calcium alginate microparticles for oral administration: II. Effect of formulation factors on drug release and drug entrapment efficiency. Journal of Microencapsulation 1999; 16(3) 291-301.

[210] Huguet, ML., Dellacherie, E. Ca-alginate beads coated with chitosan: effect of the structure of encapsulated materials on their release. Process Biochemistry 1996; 31(8) 745-751.

[211] Van Ooteghem M. M. Biopharmaceutics of Ocular Drug Delivery, CRC Press, Boca Raton,, in: P. Edman (Ed. ) 1993; 27-41.

[212] Yan, XL., Khor, E., Lim, LY. Chitosan-alginate films prepared with chitosan of different molecular weights. Journal of Biomedical Materials Research 2001; 58(4) 358-365.

[213] Motwani, SK., Chopra, S., Talegaonkar, S., Kohli, K., Ahmad, FJ., Khar, RK. Chitosan-sodium alginate nanoparticles as submicroscopic reservoirs for ocular delivery: Formulation, optimization and in vitro characterization. European Journal of Pharmaceutics and Biopharmaceutics 2008; 68(3) 513-525.

[214] Feiger, AD., Rickels, K., Rynn, MA., Zimbroff, DL., Robinson, DS. Selegiline transdermal system for the treatment of major depressive disorder: an 8-week, double-blind, placebo-controlled, flexible-dose titration trial. Journal of Clinical Psychiatry 2006; 67(9) 1354-1361.

[215] Boriwanwattanarak, P., Ingkaninan, K., Khorana, N., Viyoch, J. Development of curcuminoids hydrogel patch using chitosan from various sources as controlled release matrix. International Journal of Cosmetic Science 2008; 30(3) 205-18. 
[216] Giri, TK., Thakur, A., Alexander, A., Badwaik, AH., Tripathi, DK. Modified chitosan hydrogels as drug delivery and tissue engineering systems: present status and applications. Acta Pharma Sinic B 2012; 2(5) 439-449.

[217] Hoemann, CD., Hurtig, M., Rossomacha, E., Sun, J., Chevrier, A., Shive, MS. Buschmann, MD. Chitosan-glycerol phosphate/blood implants improve hyaline cartilage repair in ovine microfracture defects. Journal of bone and joint surgery 2005; 87(12) 2671-86.

[218] Hoemann, CD., Sun, J., McKee, MD., Chevrier, A., Rossomacha, E., Rivard, GE., Hurtig, M., Buschmann, MD. Chitosan-glycerol phosphate/blood implants elicit hyaline cartilage repair integrated with porous subchondral bone in microdrilled rabbit defects. Osteoarthritis and Cartilage 2007; 15(1) 78-89.

[219] Hu, Q., Li, B., Wang, M., Shen, J. Preparation and characterization of biodegradable chitosan/hydroxyapatite nanocomposite rods via in situ hybridization: a potential material as internal fixation of bone fracture. Biomaterials 2004; 25(5) 779-85.

[220] Yin, Y., Ye, F., Cui, J., Zhang, F., Li, X., Yao, K. Preparation and characterization of macroporous chitosan-gelatin/beta-tricalcium phosphate composite scaffolds for bone tissue engineering. Journal of Biomedical Materials Research Part A 2003; 67(3) 844-55.

[221] Zhao, F., Yin, Y., Lu, WW., Leong, JC., Zhang, W., Zhang, J., Zhang, M., Yao, K. Preparation and histological evaluation of biomimetic three dimensional hydroxyapatite/ chitosan-gelatin network composite scaffolds. Biomaterials 2002; 23(15) 3227-34.

[222] Zhao, L., Burguera, EF., Xu, HH., Amin, N., Ryou, H., Arola, DD. Fatigue and human umbilical cord stem cell seeding characteristics of calcium phosphate-chitosan-biodegradable fiber scaffolds. Biomaterials 2010; 31(5) 840-7.

[223] Li, J., Pan, J., Zhang, L., Guo, X., Yu, Y. Culture of primary rat hepatocytes within porous chitosan scaffolds. Journal of Biomedical Materials Research Part A 2003; 67(3) 938-43.

[224] Li, J., Pan, J., Zhang, L., Yu, Y. Culture of hepatocytes on fructose-modified chitosan scaffolds. Biomaterials 2003; 24(13) 2317-22.

[225] Yeh, CH., Lin, PW., Lin, YC. Chitosan microfiber fabrication using a microfluidic chip and its application to cell cultures. Microfluidics and Nanofluidics 2010; 8(1) $115-21$.

[226] Chae S. Y., Jang M. K., Nah J. W., Influence of molecular weight on oral absorption of water soluble chitosans. Journal of Controlled Release. 2005; 102, 383-394.

[227] Zheng F., Shi X. W., Yang G. F., Gong L. L., Yuan H. Y., Cui Y. J., Wang Y., Du Y. M., $\mathrm{Li}$ Y. Chitosan nanoparticle as gene therapy vector via gastrointestinal mucosa administration: results of an in vitro and in vivo study. Life Sciences. 2007; 80, 388-396. 
[228] Ishii T., Okahata Y., Sato T., Mechanism of cell transfection with plasmid/chitosan complexes, Biochimica et Biophysica Acta. 2001; 1514, 51-64.

[229] Leong K. W., Mao H. Q., Truong-Le V. L., Roy K., Walsh S. M., August J. T., DNApolycation nanospheres as non-viral gene delivery vehicles, Journal of Controlled Release. 1998; 53, 183-193.

[230] Park I. K., Kim T. H., Kim S. I., Park Y. H., Kim W. J., Akaike T., Cho C. S. Visualization of transfection of hepatocytes by galactosylated chitosan-graft-poly(ethylene glycol)/ DNA complexes by confocal laser scanning microscopy, International Journal of Pharmaceutics. 2003; 257, 103-110.

[231] Janes K. A., Fresneau M. P., Marazuela A., Fabra A., Alonso M. J. Chitosan nanoparticles as delivery systems for doxorubicin, Journal of Controlled Release. 2001; 73, 255267.

[232] Nam H. Y., Kwon S. M., Chung H., Lee S. Y., Kwon S. H., Jeon H., Kim Y., Park J. H., Kim J., Her S., Oh Y. K., Kwon I. C., Kim K., Jeong S. Y. Cellular uptake mechanism and intracellular fate of hydrophobically modified glycol chitosan nanoparticles, Journal of Controlled Release. 2009; 135, 259-267.

[233] Dodane V., Vilivalam V. D. Pharmaceutical applications of chitosan, Pharmaceutical Science \& Technology Today. 1998; 1, 246-253.

[234] Taharaa K., Sakai T., Yamamoto H., Takeuchi H., Hirashimab N., Kawashim Y. Improved cellular uptake of chitosan-modified PLGA nanospheres by A549 cells. International Journal of Pharmaceutics. 2009; 382, 198-204.

[235] Liu J., Bauer H., Callahan J., Kopečková P., Pan H., Kopeček J. Endocytic uptake of a large array of HPMA copolymers: Elucidation into the dependence on the physicochemical characteristics. Journal of Controlled Release. 2010; 143, 71-79.

[236] Chiu Y. -L., Ho Y. -C., Chen Y. -M., Peng S. -F., Ke C. -J., Chen K. -J., Mi F. -L., Sung H. -W. The characteristics, cellular uptake and intracellular trafficking of nanoparticles made of hydrophobically-modified chitosan. Journal of Controlled Release. 2010; $146,152-159$.

[237] Amiji, MM., Lai, PK., Shenoy, DB., Rao, M. Intratumoral administration of paclitaxel in an in situ gelling poloxamer 407 formulation. Pharmaceutical Development and Technology 2002; 7(2) 195-202.

[238] El-Kamel, AH. In vitro and in vivo evaluation of pluronic F127-based ocular delivery system for timolol maleate. International Journal of Pharmaceutics 2002; 241(1) 4755.

[239] Rehman, T., Tavelin, S., Gröbner. G. Chitosan in situ gelation for improved drug loading and retention in poloxamer 407 gels. International Journal of Pharmaceutics 2011; 409(1-2) 19-29. 
[240] Strappe, PM., Hampton, DW., Cachon-Gonzalez, B., Fawcett, JW., Levera, A. Delivery of a lentiviral vector in a Pluronic F-127 gel to cells of the central nervous system. European Journal of Pharmaceutics and Biopharmaceutics 2005; 61(3) 126-133.

[241] Alpar, HO., Somavarapu, S., Atuah, KN., Bramwell, VW. Biodegradable mucoadhesive particulates for nasal and pulmonary antigen and DNA delivery. Advanced Drug Delivery Reviews 2005; 57(3) 411-30.

[242] Illum, L., Watts, P., Fisher, AN., Hinchcliffe, M., Norbury, H., Jabbal-Gill, I., Nankervis, R., Davis, SS. Intranasal delivery of morphine. Journal of Pharmacology and Experimental Therapeutics 2002; 301(1) 391-400.

[243] Jain, SK., Chourasia, MK., Jain, AK., Jain, RK., Shrivastava, AK. Development and characterization of mucoadhesive microspheres bearing salbutamol for nasal delivery. Drug Delivery 2004; 11(2) 113-22.

[244] Yu, SY., Zhao, Y., Wu, F., Zhang, X., Lü, W., Zhang, H., Zhang, Q. Nasal insulin delivery in the chitosan solution: In vitro and in vivo studies. International Journal of Pharmaceutics 2004; 281(1-2) 11-23.

[245] Chung, TW., Wang, SS., Tsaia, WJ. Accelerating thrombolysis with chitosan-coated plasminogen activators encapsulated in poly-(lactide-coglycolide) (PLGA) nanoparticles. Biomaterials 2008; 29(2) 228-237.

[246] Ungaro, F., d’Emmanuele di Villa Bianca, R., Giovino, C., Miro, A., Sorrentino, R., Quaglia, F., La Rotonda, MI. Insulin-loaded PLGA/cyclodextrin large porous particles with improved aerosolization properties: In vivo deposition and hypoglycaemic activity after delivery to rat lungs. Journal of Controlled Release 2009; 135(1) 25-34.

[247] Chung, TW., Liu, DZ., Yang, JS. Effects of interpenetration of thermo-sensitive gels by crosslinking of chitosan on nasal delivery of insulin: In vitro characterization and in vivo study. Carbohydrate Polymers 2010; 82(2) 316-322.

[248] Lang, JC. Ocular drug delivery conventional ocular formulations. Advanced Drug Delivery Reviews 1995; 16(1) 39-43.

[249] Bourlais, CL., Acar, L., Zia, H., Sado, PA., Needham, T., Leverge, R. Ophthalmic drug delivery systems: recent advances. Progress in Retinal and Eye Research 1998; 17(1) 33-58.

[250] Losa, C., Marchal-Heussler, L., Orallo, F., Vila-Jato, JL., Alonso, MJ. Design of new formulations for topical ocular administration: polymeric nanocapsules containing metipranolol. Pharmaceutical Research 1993; 10(1) 80-87.

[251] Antunes, F. E. ; Gentile, L. ; Rossi, C. O. ; Tavano, L. ; Ranieri, G. A. Gels of Pluronic F127 and nonionic surfactants from rheological characterization to controlled drug permeation. Colloids Surf. B Biointerfaces. 2011, 87(1), 42-8.

[252] Van der Merwe S. M, Verhoef J. C., Kotze A. F, Junginger H. E. N-trimethyl chitosan chloride as absorption enhancer in oral peptide drug delivery. Development and 
characterization of minitablet and granule formulations. European Journal of Pharmaceutics and Biopharmaceutics 2004; 57, 85-91.

[253] Bhumkar D. R., Joshi H. M., Sastry M., Pokharkar V. B. Chitosan reduced gold nanoparticles as novel carriers for transmucosal delivery of insulin. Pharmaceutical Research 2007, 24, 1415-1426.

[254] Kang, M. L., Cho, C. S., Yoo, H. S. Application of chitosan microspheres for nasal delivery of vaccines. Biotechnology Advances 2009; 27(6) 857-865.

[255] Gallaher C. M., Munion, J., Hesslink Jr., R., Wise, J., Gallaher, D. D. Cholesterol reduction by glucomannan and chitosan is mediated by changes in cholesterol absorption and bile acid and fat excretion in rats. Journal of Nutrition, 2000; 130, 2753-2759.

[256] Yao H-T, Huang S-Y, Chiang M-T. A comparative study on hypoglycemic and hypocholesterolemic effects of high and low molecular weight chitosan in streptozotocininduced diabetic rats. Food and Chemical Toxicology. 2008, 46, 1525-1534.

[257] Lee, H. W., Park, Y. S., Choi, J. W., Yi, S. Y., Shin, W. S. Antidiabetic effects of chitosan oligosaccharides in neonatal streptozotocin induced noninsulin-dependent diabetes mellitus in rats. Biological Pharmaceutical Bulletin, 2003, 26, 1100-1103.

[258] Kondo Y., Nakatani, A., Hayash, K., Ito, M. Low molecular weight chitosan prevents the progression of low dose streptozotocininduced slowly progressive diabetes mellitus in mice. Biological Pharmaceutical Bulletin, 2000, 23, 1458-1464.

[259] Hayashi, K., Ito, M. Antidiabetic action of low molecular weight chitosan in genetically obese diabetic KK-Ay mice. Biological Pharmaceutical Bulletin, 2002, 25, 188192.

[260] Wu Z. -H., Ping Q. -N., Wei Y., Lai J. -M. Hypoglycemic efficacy of chitosan-coated insulin liposomes after oral administration in mice. Acta Pharmacologica Sinica. 2004; 25 (7) 966-972.

[261] Hombach J, Bernkop-Schnürch A. Chitosan solutions and particles: Evaluation of their permeation enhancing potential on MDCK cells used as blood brain barrier model. International Journal of Pharmaceutics, 2009; 376, 104-109.

[262] Borchard G., Luessen, H. L., deBoer, A. G., Verhoef, J. C., Lehr, C. M., Junginger, H. E. The potential of mucoadhesive polymers in enhancing intestinal peptide drug absorption. 3. Effects of chitosan-glutamate and carbomer on epithelial tight junctions in vitro. Journal of Controlled Release. 1996, 39, 131-138. 
